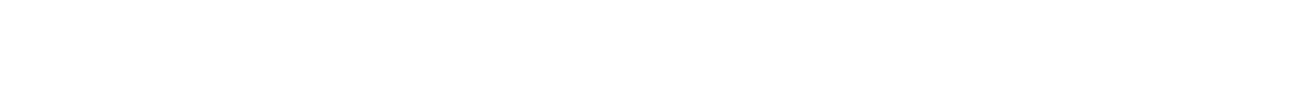

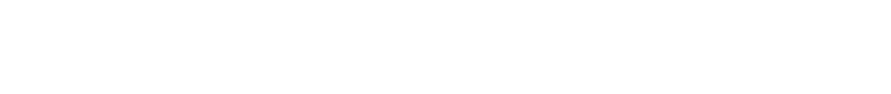

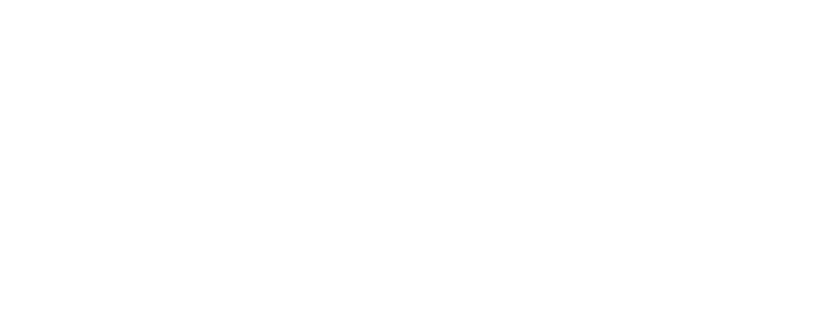

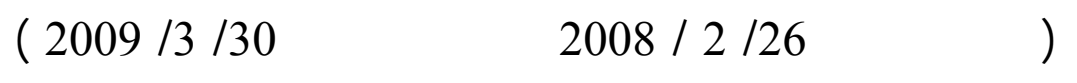

\section{الملغص}

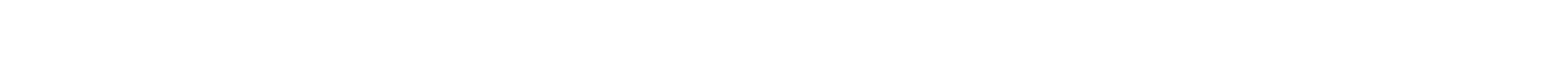

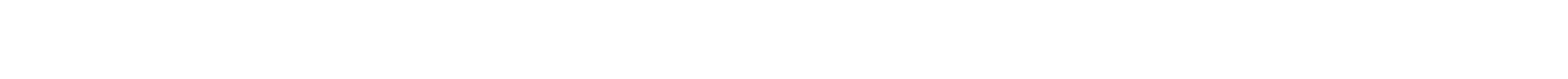

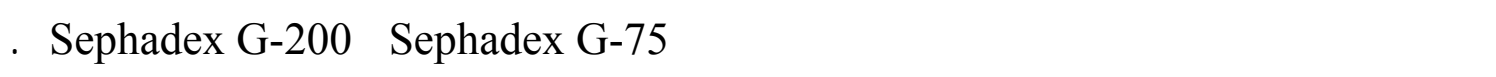

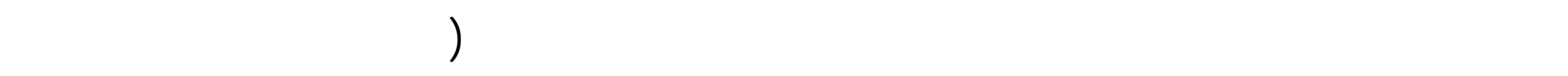

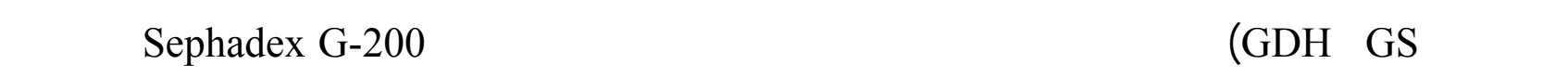

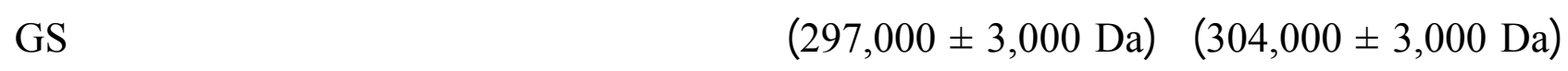

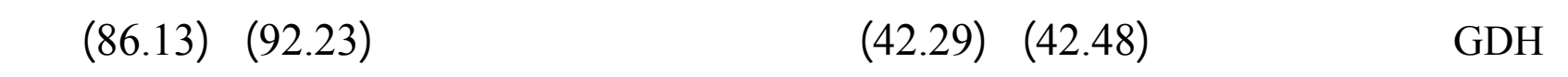
على التوالي للنسبج المصلب.

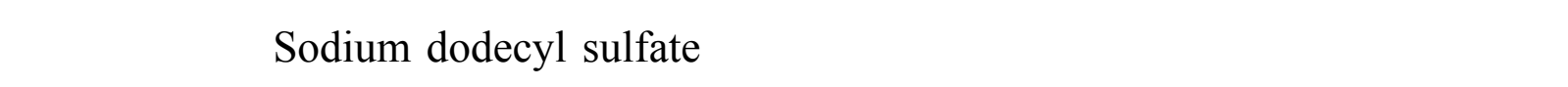

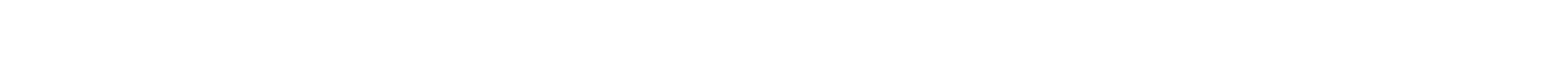
(42,600 Da) الكلى السليم والمصلب متشابه وبحدود (52,60 (53,900)

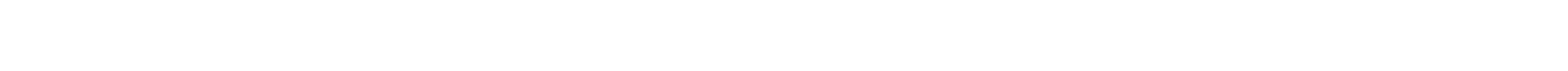

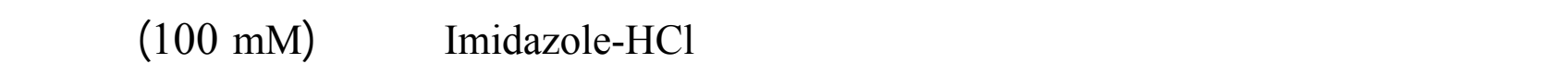

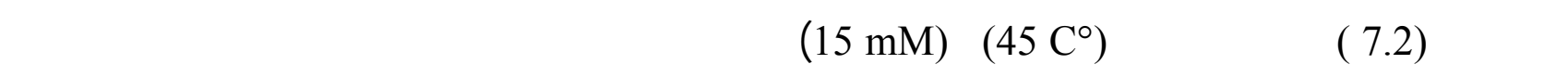

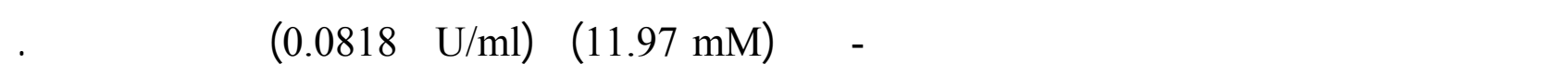

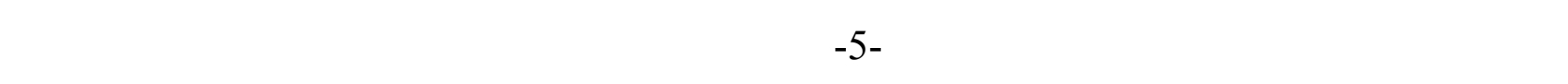

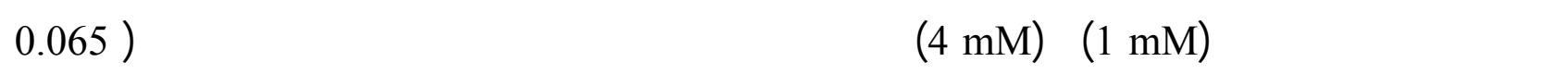




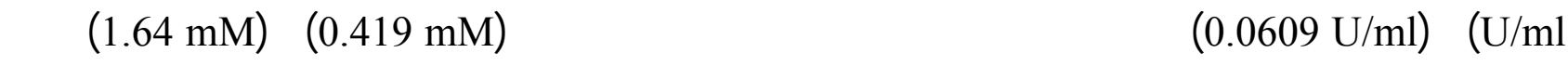
التوالي بلستخدله بسم لاينويفر-برك .

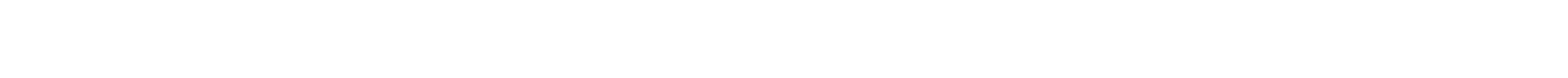
بلستخدلم المحلول المظم Tris-HCl بتركيز(100 mM) وبدالة حلمضية (8.8) ودرجة حرارة(

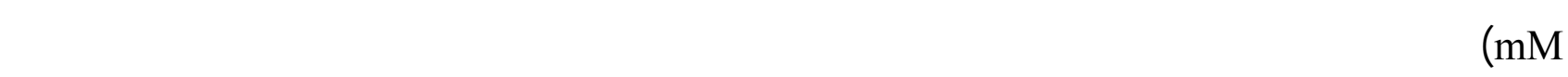

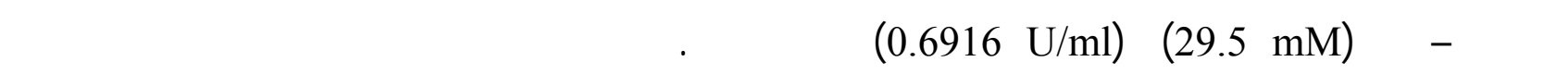

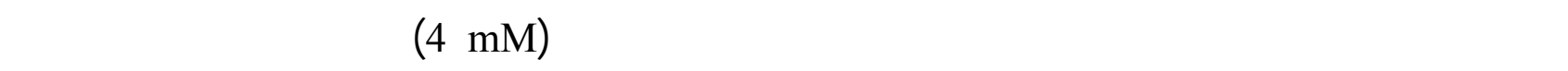

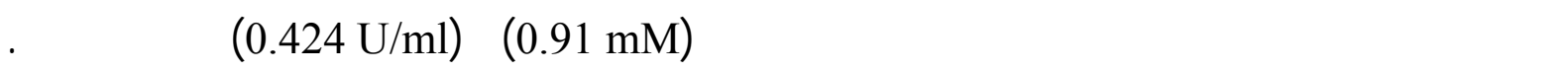

\title{
Isolation of Glutamine Synthetase and Glutamate Dehydrogenase from Normal and Renal Cell Carcinoma Human kidney's Tissue
}

\author{
Tareq Y. Ahmad \\ Mahmoud A. Mohammad \\ Department of Chemistry \\ College of Science \\ Mosul University
}

\begin{abstract}
The research included isolation of glutamine synthetase and glutamate dehydrogenase from normal \& tumor human kidney's tissue using different biological techniques, These included ammonium sulfate precipitation, dialysis, gel filtration chromatography on sephadex G-75 and sephadex G-200 .

It was shown that, the comparative molecular weight of the second proteinous peak (produced from sephadex G-200 colum, also it contain glutamine synthetase and glutamate dehydrogenase activity) for normal \& tumor kidney's tissue was found to be $(304,000 \pm$ $3,000 \mathrm{Da})$ and $(297,000 \pm 3,000 \mathrm{Da})$ respectively, And the purification of glutamine synthetase and glutamate dehydrogenase in this peak was (42.48 fold) and (42.29 fold) respectively for normal kidney's tissue, $(92.23$ fold) and ( 86.13 fold) respectively for tumor kidney's tissue.

Further more, the comparative molecular weight of the subunit of glutamine synthetase and glutamate dehydrogenase were determined by sodium dodecyl sulfate-polyacrylamide electrophoresis techniques for normal and tumor kidney's tissue and found to be $(42,600$ $\mathrm{Da})$ and $(53,900 \mathrm{Da})$ respectively .

The results also showed that the optimum conditions of glutamine synthetase were obtained using imidazole- $\mathrm{HCl}(100 \mathrm{mM})$ as a buffer at $\mathrm{pH}(7.2),\left(45 \mathrm{C}^{\circ}\right)$ and $(15 \mathrm{mM})$ of glutamate as a substrate. Using Linweaver-Burk plot, it was found that $\mathrm{V}_{\max }$ and $\mathrm{K}_{\mathrm{m}}$ have the values of $(0.0818 \mathrm{U} / \mathrm{ml}),(11.97 \mathrm{mM})$ respectively. The effect of ammonium chloride
\end{abstract}


and adenosine-5-triphosphate concentration on the enzyme activity were also preformed. The optimum concentration of ammonium chloride is $(1 \mathrm{mM})$ with $\mathrm{V}_{\max }(0.065 \mathrm{U} / \mathrm{ml})$ and $\mathrm{K}_{\mathrm{m}}(0.419 \mathrm{mM})$. On the other hand, the optimum concentration of adenosine-5-triphosphate is $(4 \mathrm{mM})$ with $\mathrm{V}_{\max }(0.0609 \mathrm{U} / \mathrm{ml})$ and $\mathrm{K}_{\mathrm{m}}(1.64 \mathrm{mM})$.

Finally, The optimum conditions of glutamate dehydrogenase were obtained using Tris- $\mathrm{HCl}(100 \mathrm{mM})$ as a buffer at $\mathrm{pH}(8.8),\left(40 \mathrm{C}^{\circ}\right)$ and $(50 \mathrm{mM})$ of glutamate as a substrate. Using Linweaver-Burk plot, it was found that $\mathrm{V}_{\max }$ and $\mathrm{K}_{\mathrm{m}}$ have the values of $(0.6916 \mathrm{U} / \mathrm{ml}),(29.5 \mathrm{mM})$ respectively. The effect of nicotinamide adenine dinucleotide concentration on the enzyme activity was also preformed. The optimum concentration of nicotinamide adenine dinucleotide is $(4 \mathrm{mM})$ with $\mathrm{V}_{\max }(0.424 \mathrm{U} / \mathrm{ml})$ and $\mathrm{K}_{\mathrm{m}}(0.91 \mathrm{mM})$.

\section{الفمدة}

للسرطلن ليس مرحلة من تحول أو نمو مرتب لمركب أو عضو في الجسم، بل هو إخفلق عضوي تلم (كارثة عضوية)، ويمكن القول بأنه مجموعة خلايا حقيقية النوة Eukaryotes مع مجموعة خلايا مقسمة منها (Zubay, 1998). إن أنواعَ من لمراض المرطلن يرافقها إنتاج غير طبيعي للأنزيملت Enzymes والبروتينت والهرمونت والتي يمكن قيلسها والتعرف عليها في مصل الهم Serum أو بلازما اله Plasma

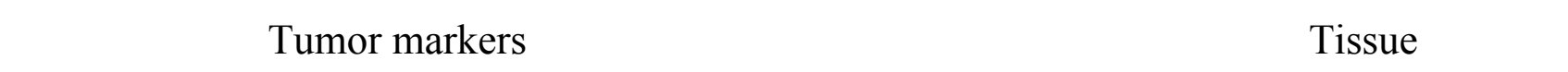
إنه ليس جمبع المرضف أو جمبع أنواع للسرطن تعطي المؤشر فسه (أو المتغير) وغالباً ما تكثف المؤثررات عن المرلكل المقدمة لكثر من المرلل الأولية للسرطل. : Edwards and Bouchier, 1991;

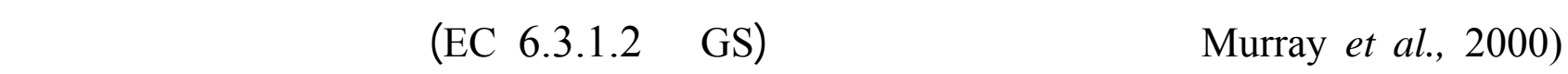
النايتروجين في كل الأحياء من البكتريا مرورَ بالنباتت والحيوانت، وهو أذزيم متعدد الوحدات ، يحفز تحول الكلوتلميت والامونيا إلى كلوتلمين إعتمادَ على الاسينوسن -'5 - ثلاثي الفوسفلت لئل 1994). وتعزى وظفة الأززيم إلى ثمانية وحدات فرعية متماثلة مع بعض الإختلافلت النوعية الطفيفة بين هذه الوحدات (Smirnov et al., 2000). ولقد لسقاع أذزيم GS أن يجذب إنتباه البلحثن في الطب بسبب

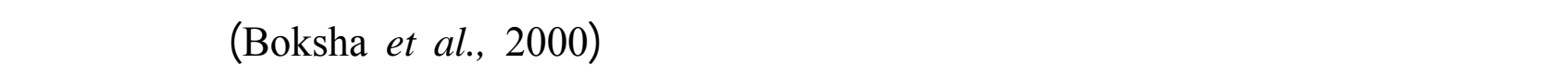
الزهايمر (LePince et al., 1995) وحالات تضضرر دماغ الثيييت(Krajnc et al., 1996). ولقد تمت تقية أذزيم كلوتلمين سنثيتيز من لماغ الإنسن وحدد الوزن الجزيئي القريبي للوحة الفرعية للأنزيم بقفنية) Sodium dodecyl sulfate-polyacrylamide gel electrophoresis (SDS-PAGE وكانت بحدود(Tumani et al., 1995 ; Boksha et al., 1995) (44,000 Da). ولشثارت الدرلست إلى أن أعلى فعالية للأنزيم في جمم الإنسان تكون في الدماغ والكبد ( Suarez et al., 2002 ). وأظلهرت الدرلست وجود ثلاثة مواقع في كل وحة فرعية من الوحدات الثمانية المكونة لأنزيم كلوتلمينسنثيتيز الإنسان يرتبط من في خلالها الكلوتلميت والأمونيا وال ـ ATP (Shin et al., 2003). 
لما ألززيم كلوتلميت ديهيدروجينيز(GDH ، GC1.4.1.2-4)، فيحفز إما إضافة الأمين الاختزالية للألفا -

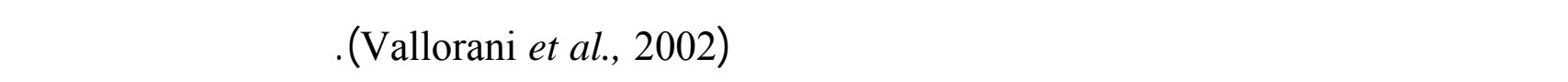

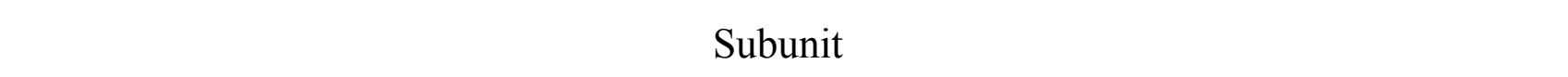

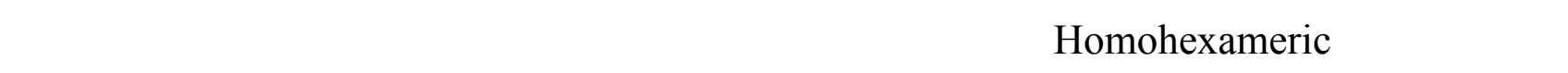
والمعتمدة على لإستخدلم NAD فتط بوصفه مررافقاً ألززيمياً حيث يتكون من أربع وحدات فرعية متماثلة Homotetrameric

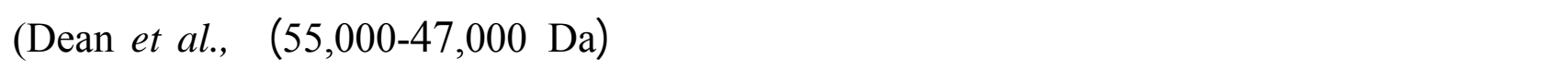
Mammalian GDH إلن أنزيم كلوتلميت ديهيدروجينيز الثييك (1997. Britton et al., 1992) (E.C.1.4.1.3)

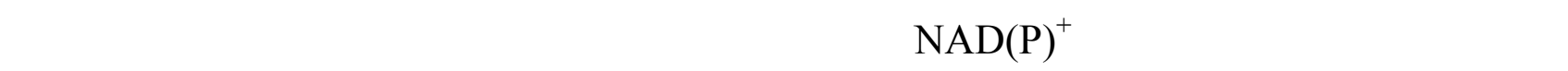

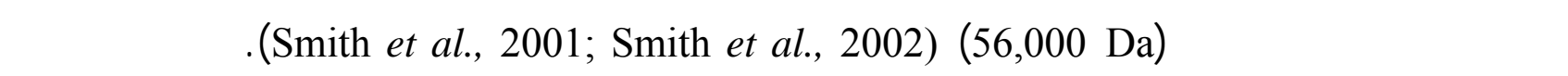

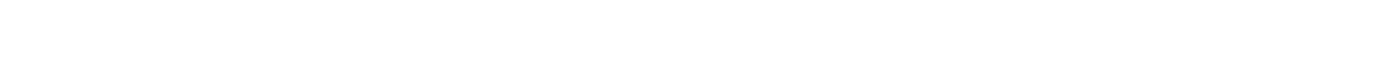

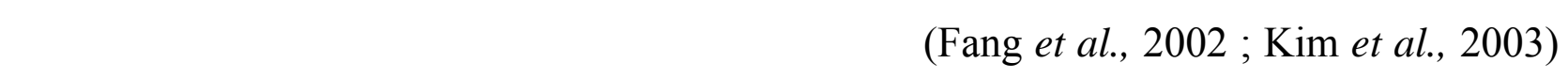

مختلفة كتشخيصه في المشيمة وكبد الأجنة Timmerman et al., 2003) Fetal liver). ويهوف البهث الحالي إلى عزل أنزيمي كلوتلمينسنثيتيز وكلوتلميت ديهيدروجينيز من سنج كلىسليم

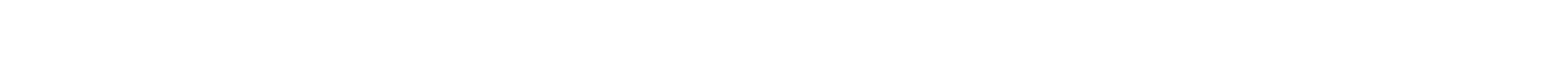
اللسليمة.

\section{المواد طرائق المل}

\section{نماذج الأنسجة:}

مُ الحصول على عينة نسبج كلى إنسان سليم من نكرسليم ظاهرياً من دائرة الطب العدلي في المابي

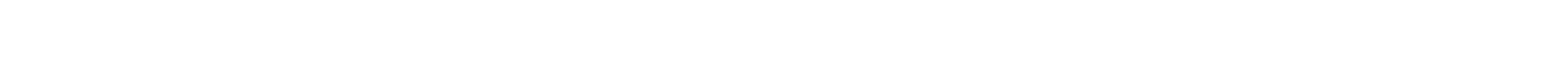

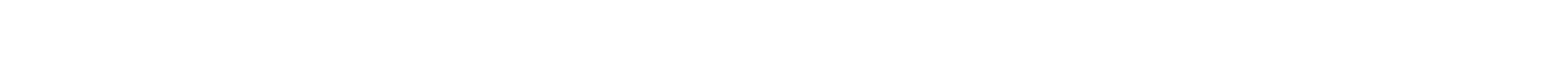
مستثف الزهراوي الأهلي (وكانت العينة المأخونة حاويةً على الورم). تحضضير نماذج الأنسجة: بعد الحصول على التطع النسيجية من صالة العمليك والطب العدلي غسلت جيداً بالماء المظرر ثم

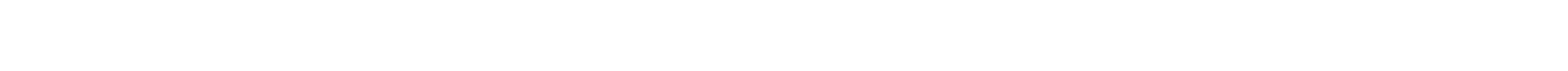

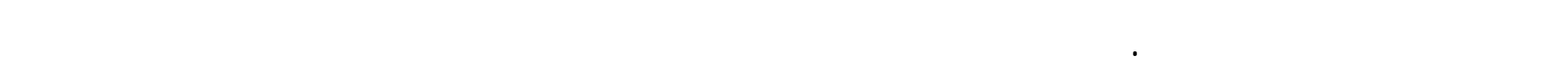


وزنها بالميزان الهسلس. إن فقدان أو عمم وجود جدار خلوي صلب في الخلية الحيولنية يجعلهاسهلة للسحق، لذك قم تظطبع العينة إلى قطع صغيرة جداًَ، وبعد أن أضضف الماء المتطر المزال الايونات إلى العينة

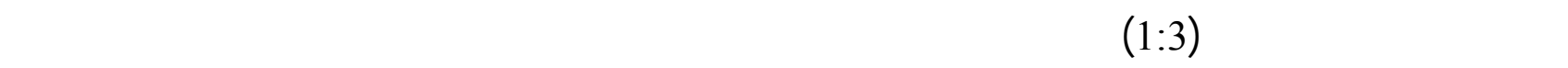
النموذج للسحق بجهاز للسحق الذاتي، بعد ذك تقل المستخلص الخلوي إلى جهاز اللسحق في حوض الترددات فوق الصوتية لمدة (40 min) ثم حرك بعد ذلك بولنطة المحرك المغنلطيسي لمدقساعتين مع مراعلة التبريد

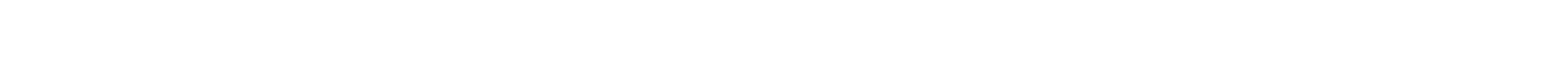

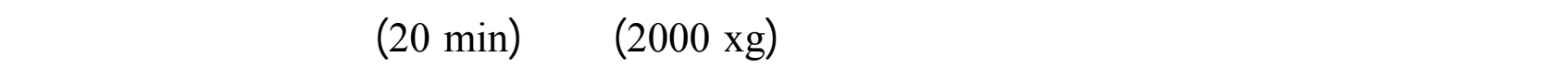

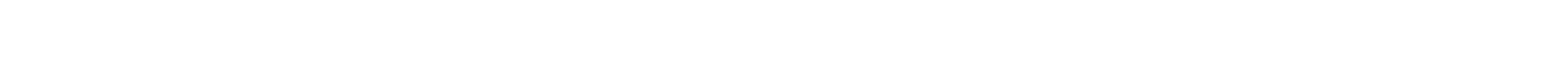

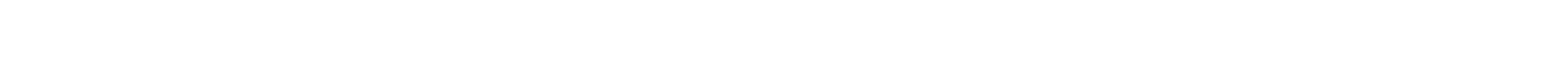
ليهيدروجينيز في ذلك المستخلص إضلفة إلى قيلس تركيز البروتين. قيلس البروتن والنهالية الأنزيمية:

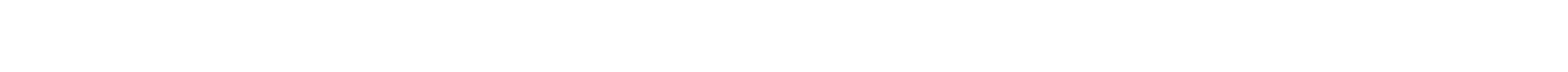

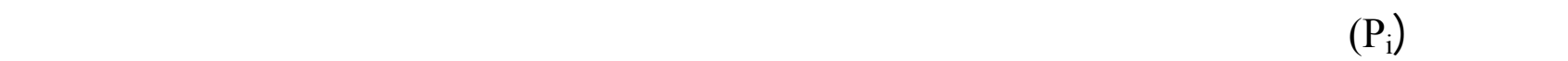
الامونيوم Ammonium molybdate الموجوة في محيط حلمضي حيث يتكون معقد الموليب دونيوم الأزرق

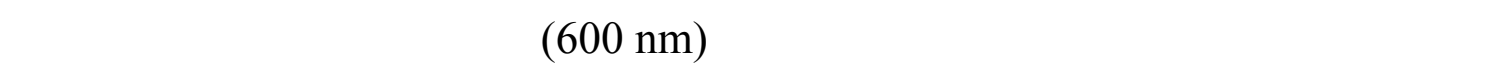

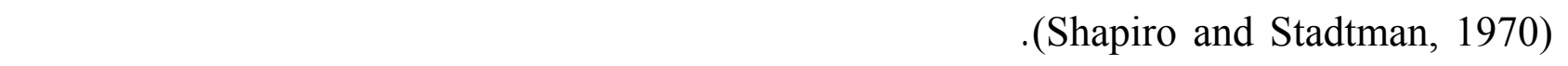
للفوسفلت (

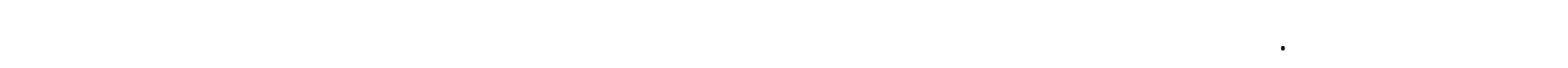

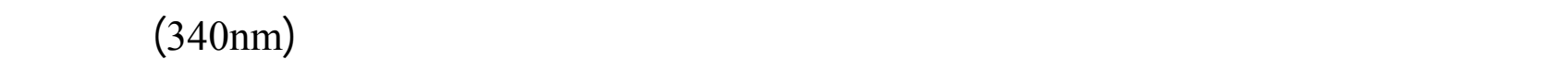
علىطريقة البلحثين(Hadži and Šukalović, 1990). وقدرت كمية البروتين ف مي مه ستخلص الأنزي - م م

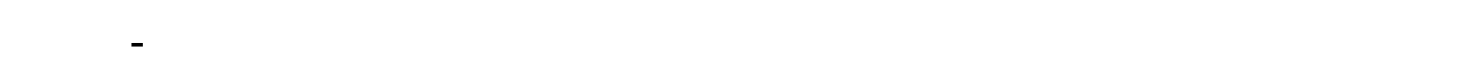
(Schacterle and Pollack, 1973) والمحورة من قل البلحئن (Lowry et al., 1951)

\section{تقية أنزيمي كلوتامينسنثيتيز وكلوتاميت نيهيروجينيزمن مستخاص ألنسجة الكلى:}

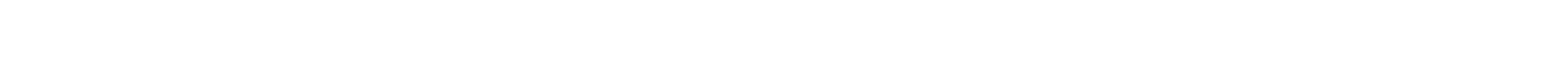
السليم والمصلب بسرطان خلايا الكلى والتي تضضمنت الأتي:

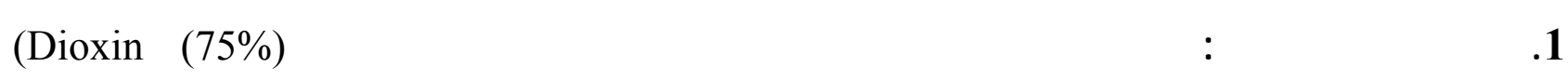

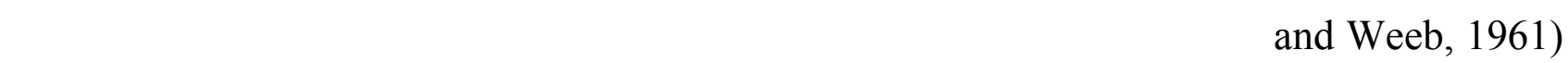

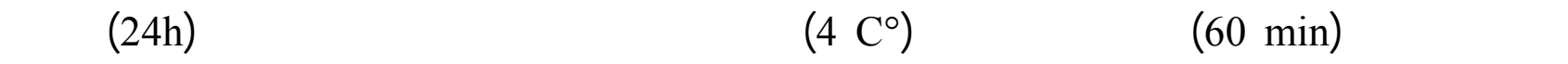


الثلاجة عند درجة حرارة (4C )، ثم فصل الرلمب عن الرلشح بجهاز الطرد المركزي بسرعة (3600 xg)

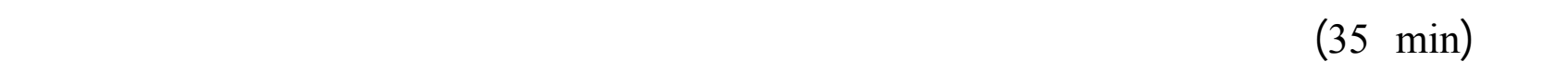

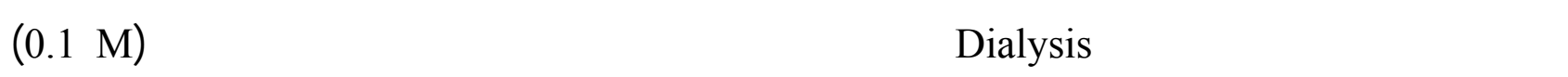

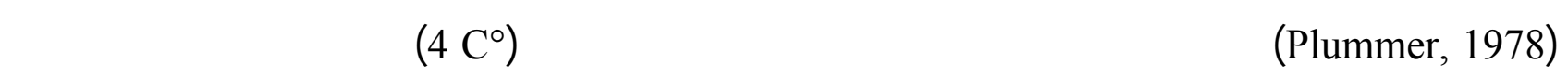

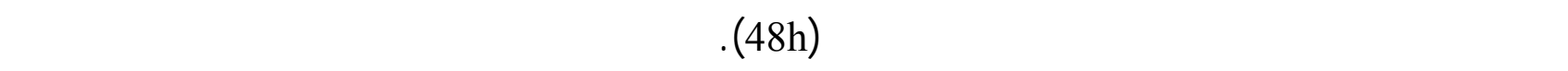

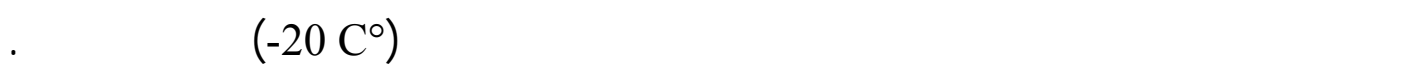

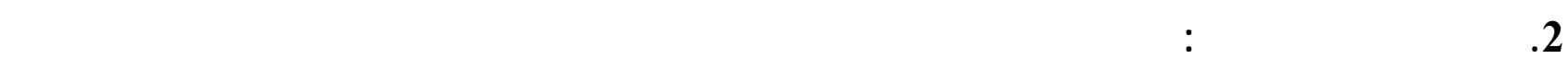

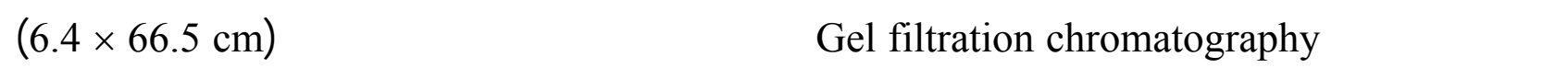

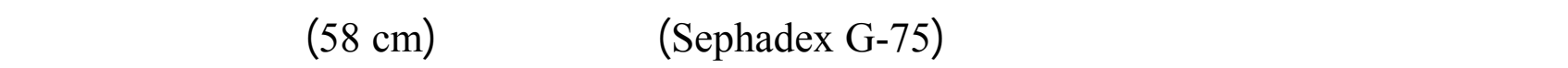

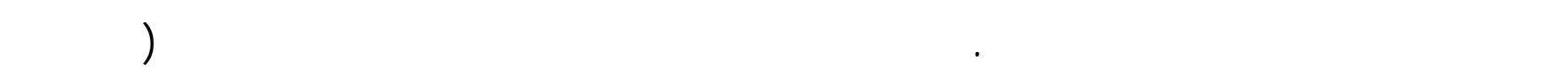

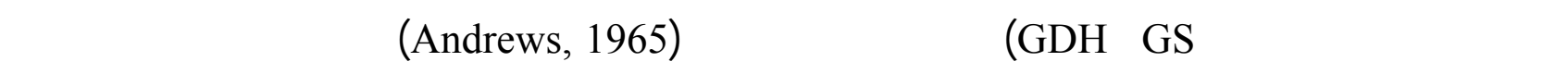

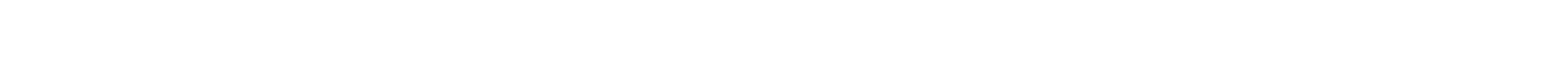
الفصل أعلاه. 3. تجزئة الحزمة البروتينية الأولى: مق تجزئة الحزمة البروتينية الأوله(الحاوية على فعالية كلا الأن _زيمين

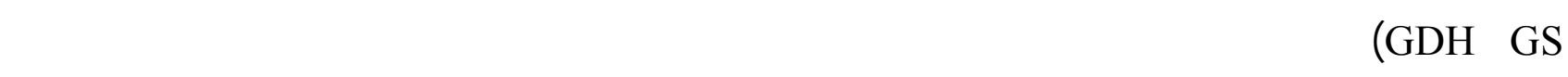

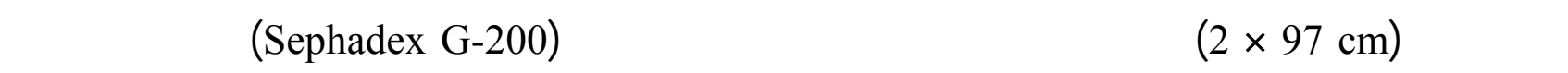

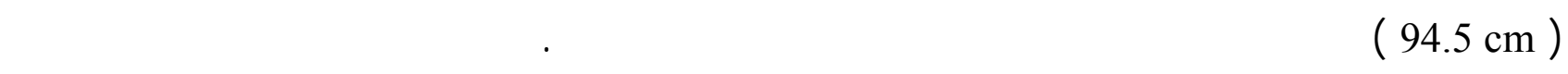

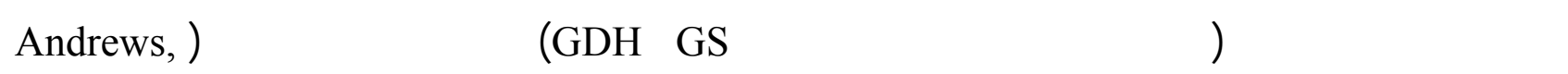

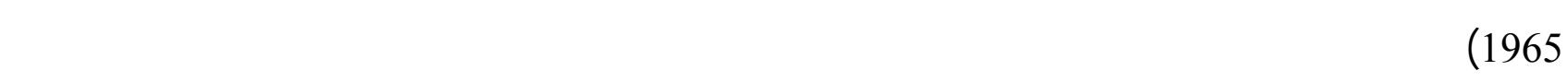
الجزيئي م إمرارها في نفس عمود الفصل أعلاه

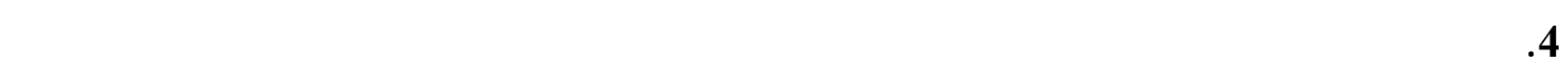

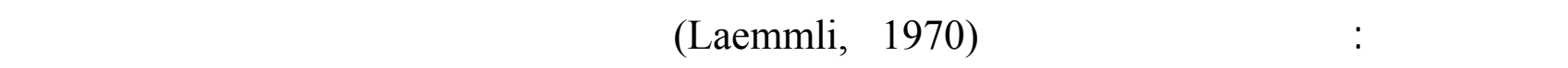

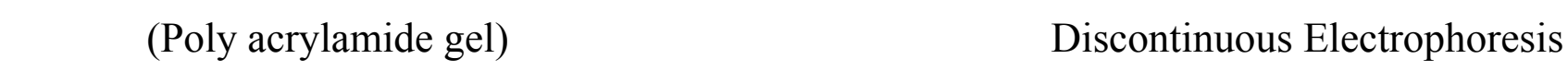

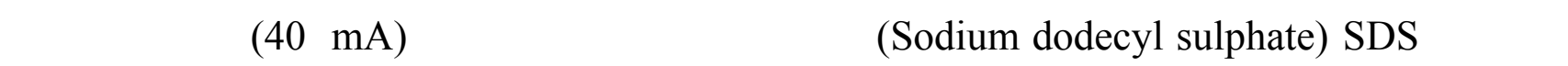

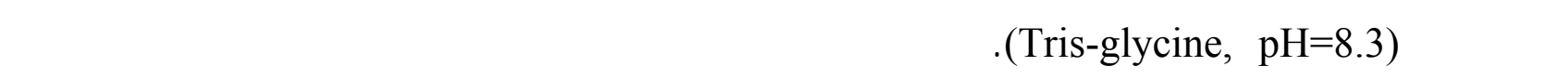

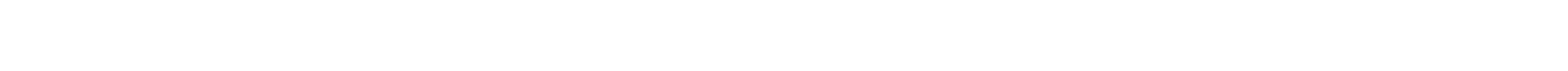

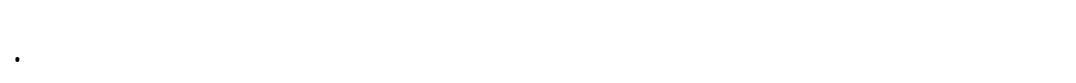




\section{النتائج والمنالثة

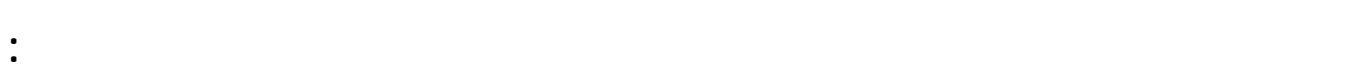

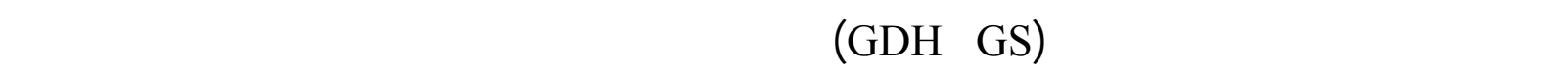

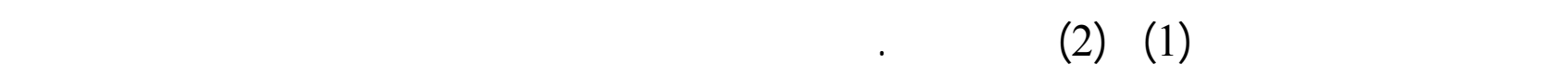

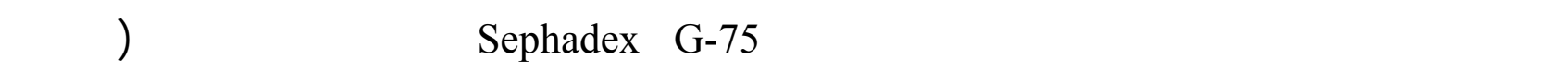

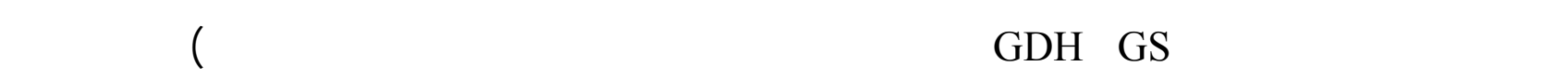

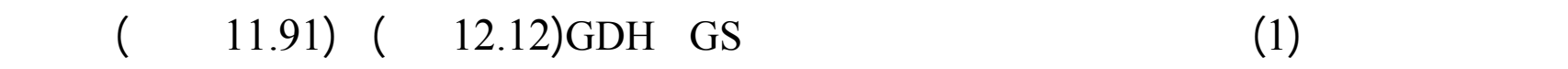

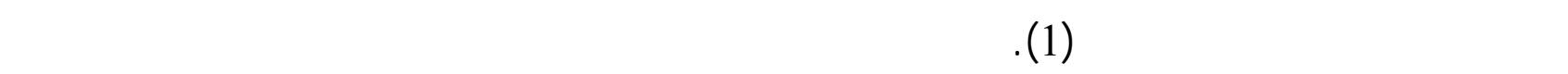

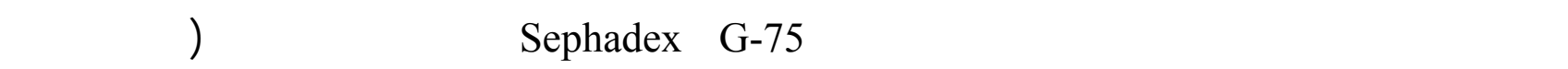

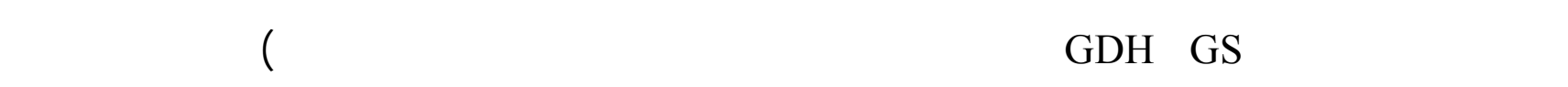

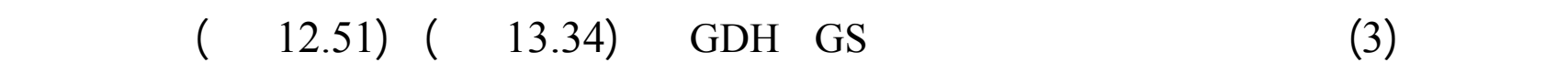

وكما هومبين في الجدول (2).

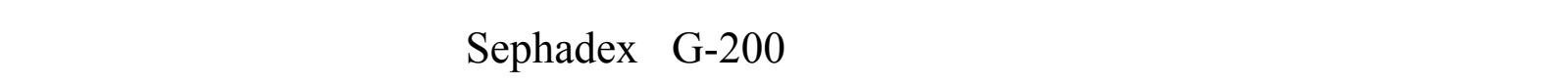

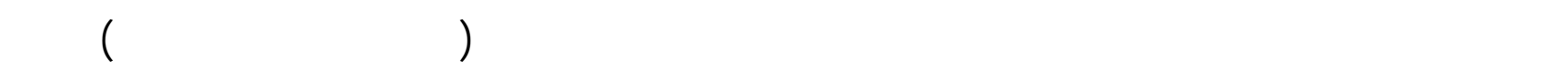

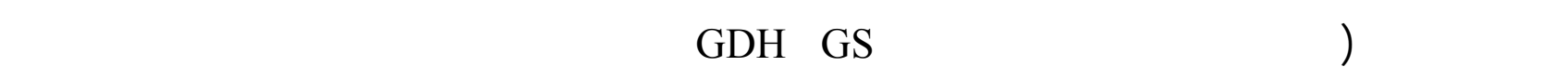

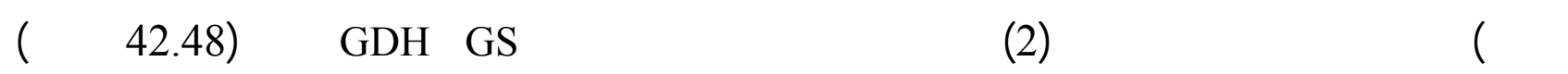

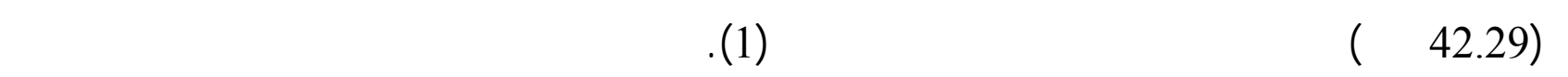

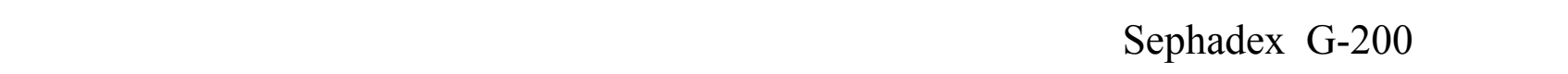

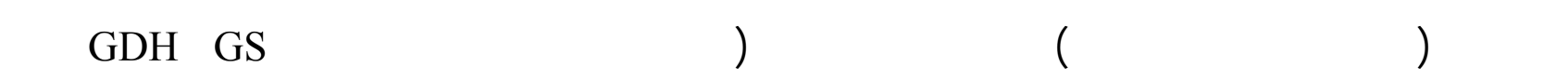

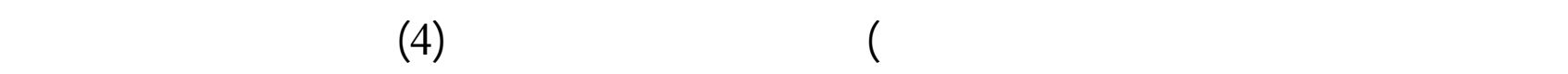

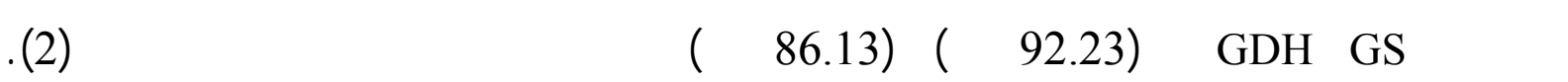

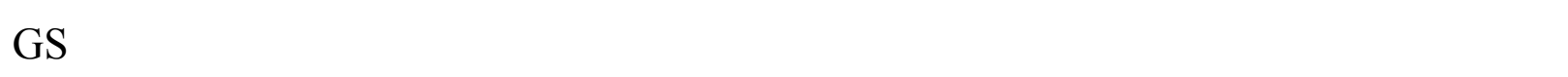

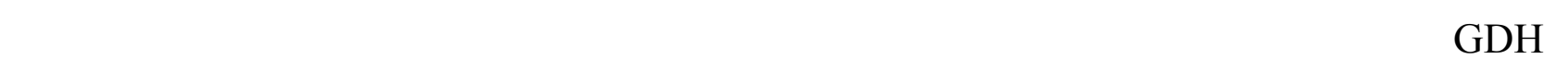

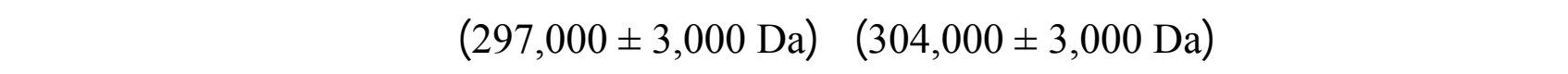

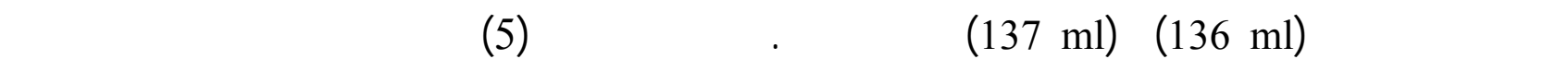

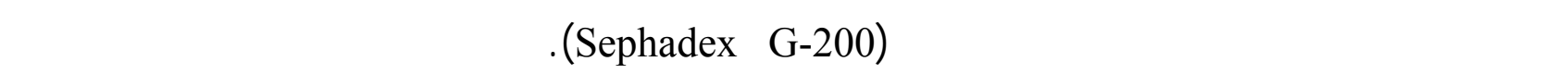

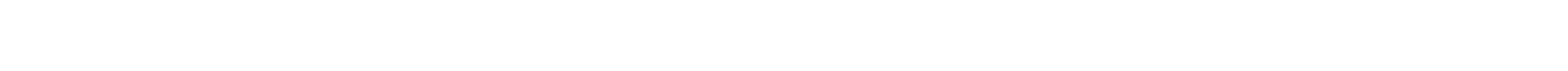
الناتجة من عمود الفطل الثاني يكون مثشايهاً. 


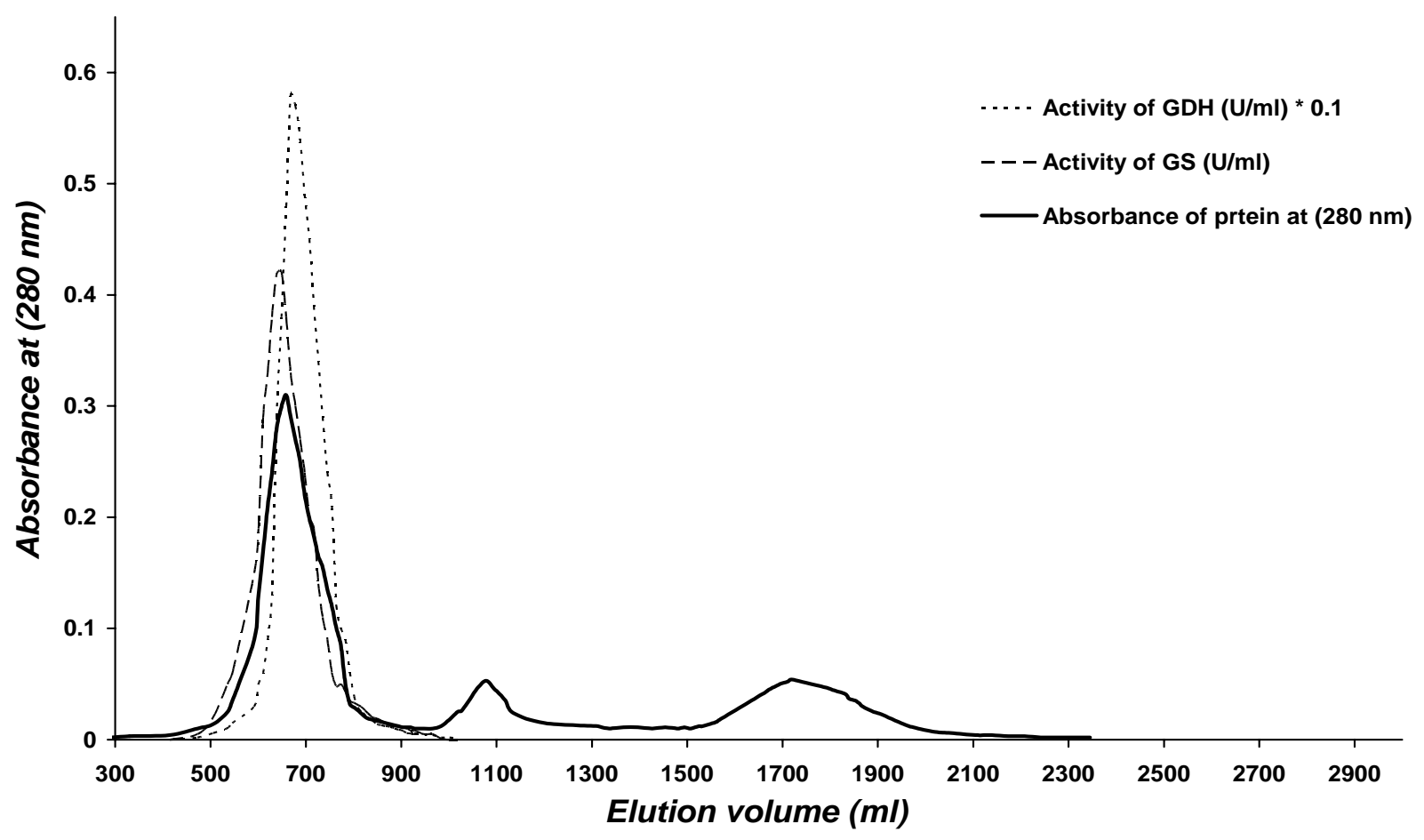

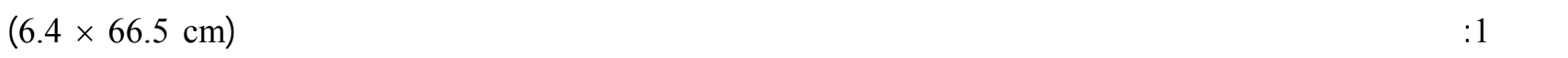

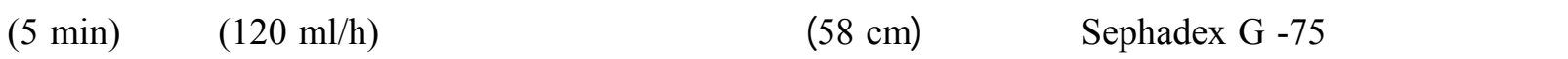

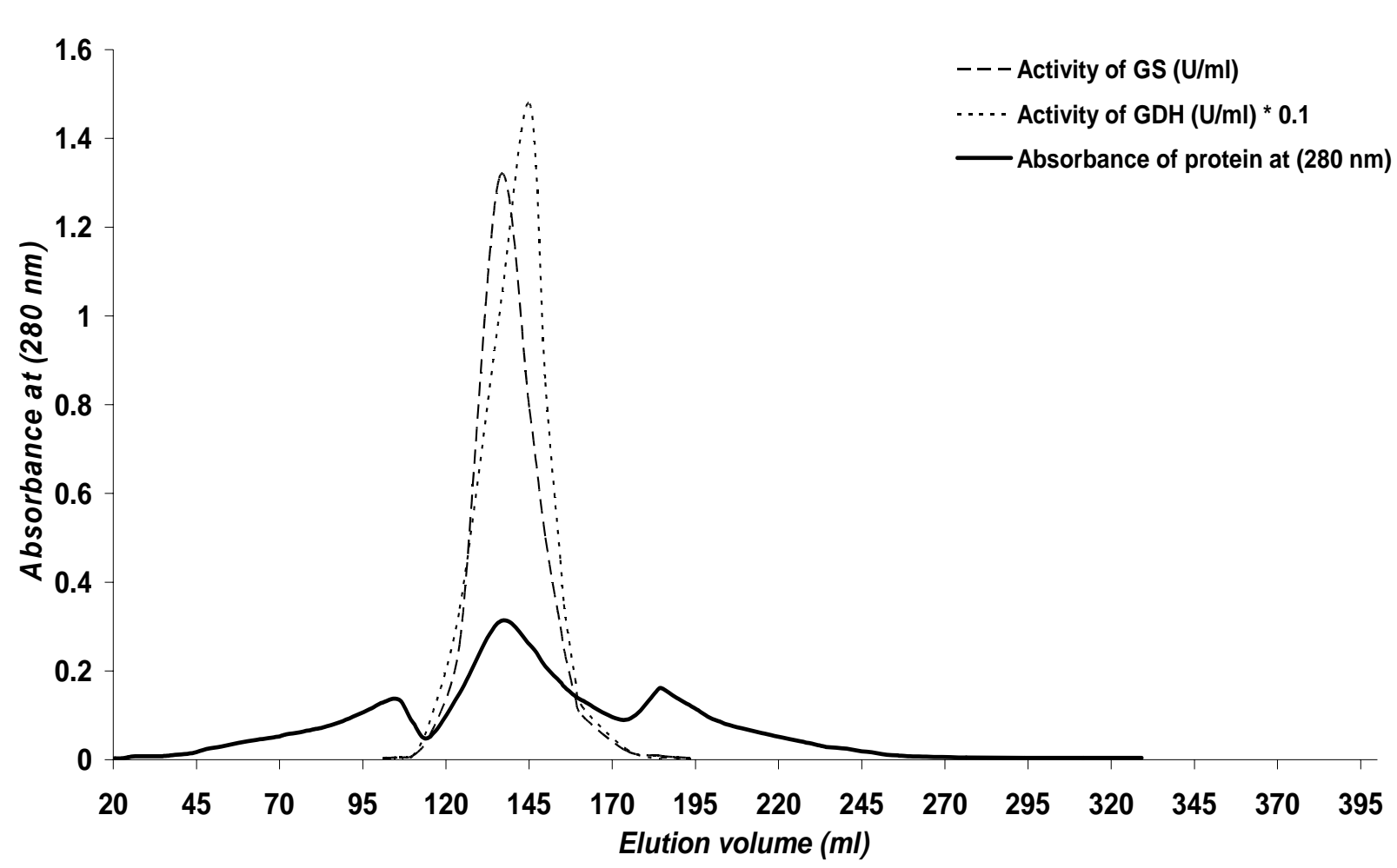

اللشكل 2: الظهر الجانبي لروغلن محلول الحزمة البروتينية الأوله الناتجة من عمود الفصل الأول والعائة لنسج الكلى للسليم على عمود الفصل الثاني ذي الإبعاد (Sephadex G -200 97 × × 2) والحاوي على ارتفاع (94.5 ) ،وتمت عملية الجمع

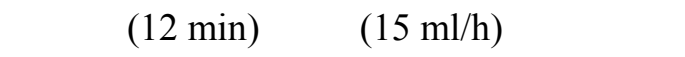




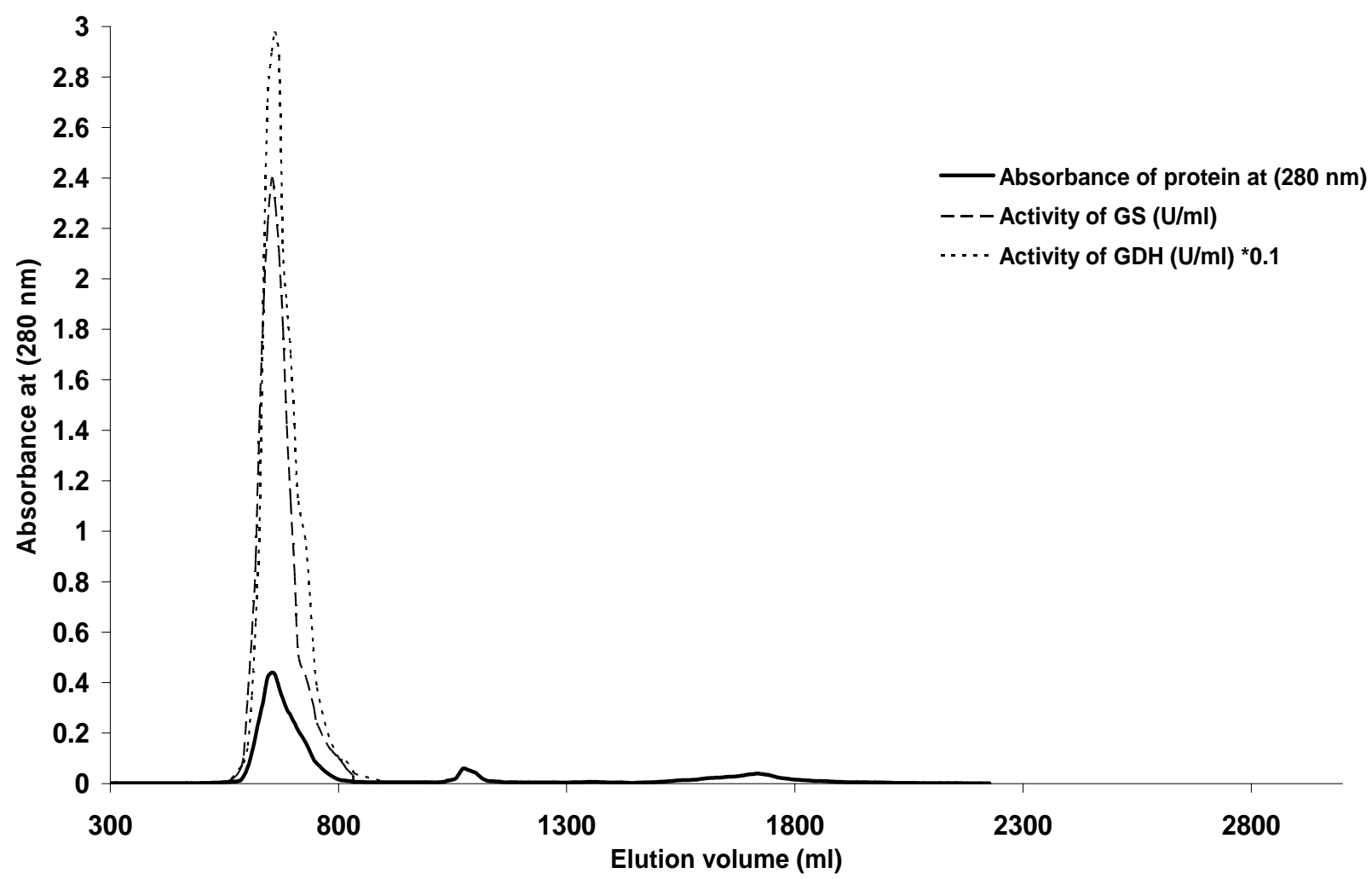

اللشكل 3: الفظهر الجانبي لروغان محلول البروتين الكلي العائد لنسبج الكلى المصل على عمود الفصل الأول ذي الإبعاد( (6m 66.5 × 6.4)

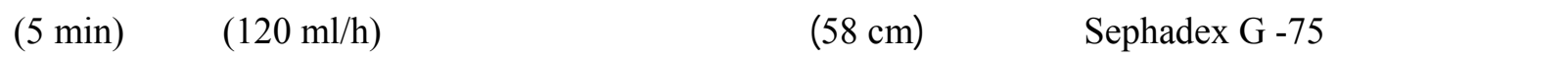

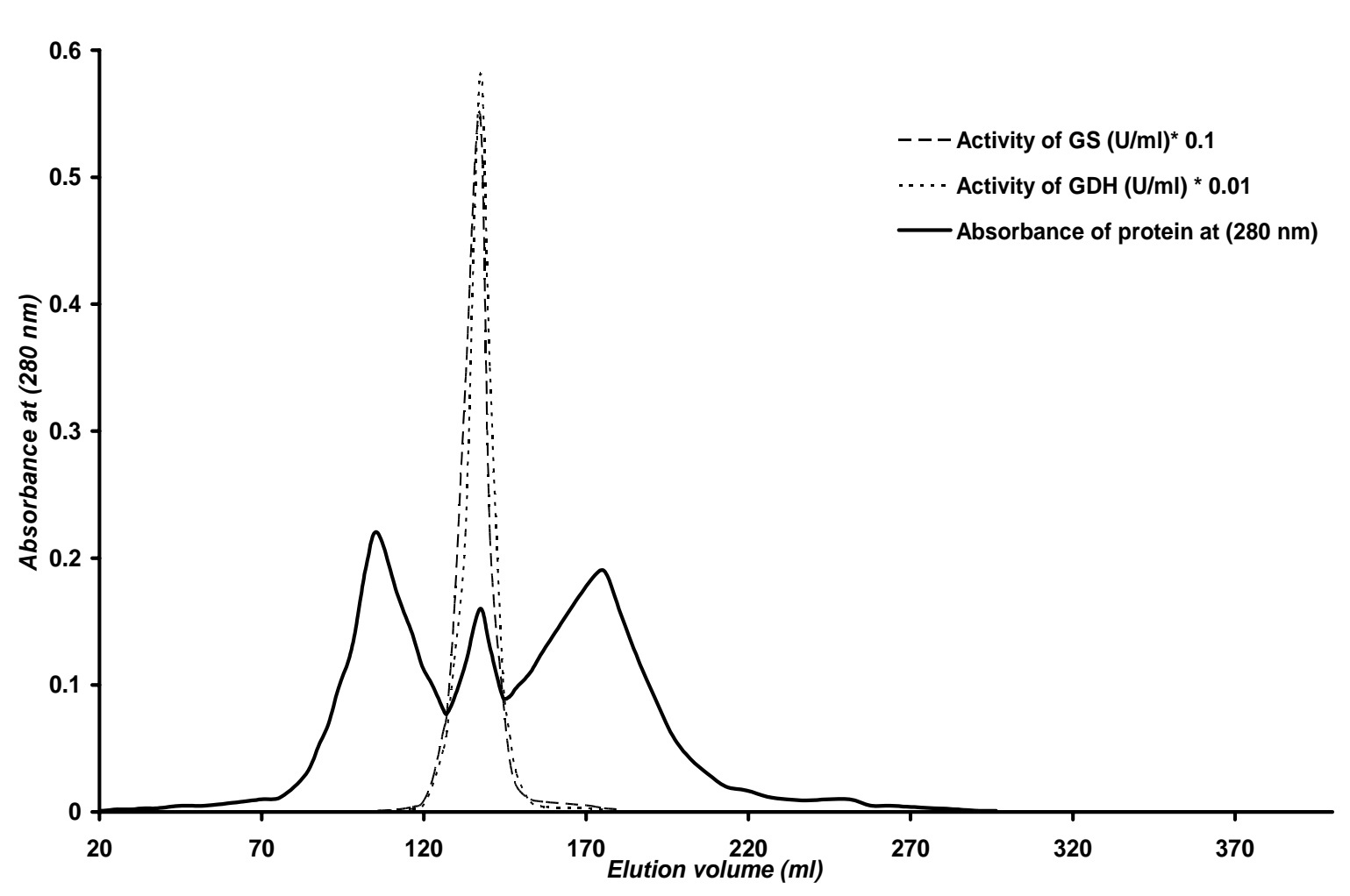

اللشكل4: الفظهر الجانبي لروغلنمحلول الحزمة البروتينية الأوله الناتجة من عمود الفصل الأول والعائة لنسبج الكلى المصب على عمود الفصل

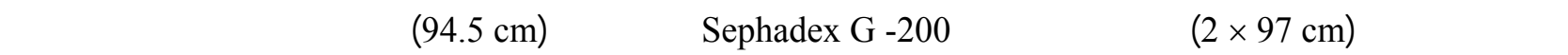


الجدول1: خلاصة نتائج مرلل تقية أنزيمي كلوتلمينسنثيتيز وكلوتلميت نيهيدروجنيز من i سبج الكا ق

\begin{tabular}{|c|c|c|c|c|c|c|c|c|c|c|}
\hline & & & & & & & & & & ل لمليم \\
\hline \% لمنتطة & مرل & $\begin{array}{l}\text { النوعية."لd } \\
\text { لأزمية } \\
\text { GDH } \\
\text { U/mg }\end{array}$ & $\begin{array}{l}\text { لألمالية } \\
\text { GDH } \\
\text { GDH } \\
{ }^{\#} \mathrm{U}\end{array}$ & \% Pلمتطلة & مرات & 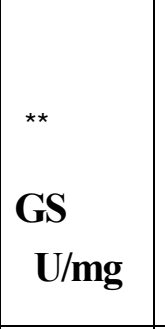 & $\begin{array}{l}\text { لأزبمة } \\
\text { GS } \\
\text { GS } \\
{ }^{*} \mathrm{U}\end{array}$ & البرونن & له لما & مرللى التقية \\
\hline 100.0 & 1.00 & 0.1508 & 122.04 & 100.0 & 1.00 & 0.0147 & 11.89 & 809.5 & 85.1 & المستخلص الخلم \\
\hline 90.0 & 1.62 & 0.2440 & 109.84 & 91.7 & 1.65 & 0.0242 & 10.90 & 450.1 & 60.5 & المستخلص الرلق \\
\hline 77.1 & 3.37 & 0.5079 & 94.12 & 81.2 & 3.54 & 0.0521 & 9.65 & 185.3 & 11.5 & 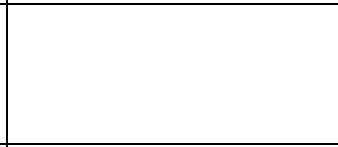 \\
\hline 69.9 & 5.47 & 0.8249 & 85.29 & 73.2 & 5.72 & 0.0841 & 8.70 & 103.4 & 13.7 & الفرز الغشائي \\
\hline 57.7 & 11.91 & 1.7962 & 70.41 & 58.7 & 12.12 & 0.1781 & 6.98 & 39.2 & 460.5 & 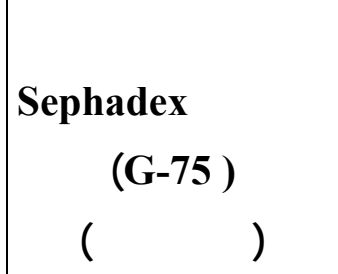 \\
\hline 44.9 & 42.29 & 6.3767 & 54.84 & 45.2 & 42.48 & 0.6224 & 5.37 & 8.6 & 58.6 & 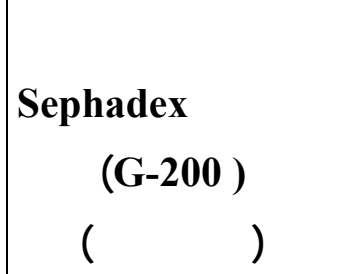 \\
\hline
\end{tabular}

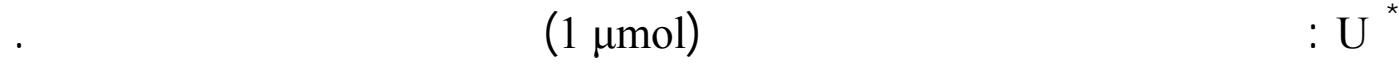

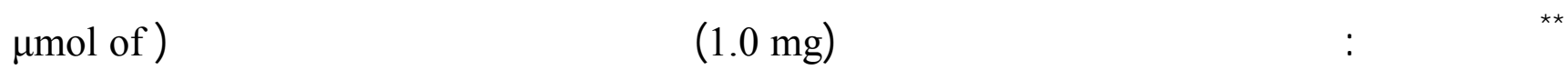
. (Pi/min $/ \mathrm{mg}$ of protein

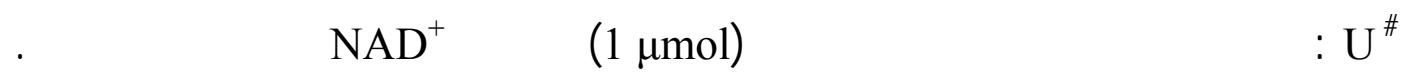

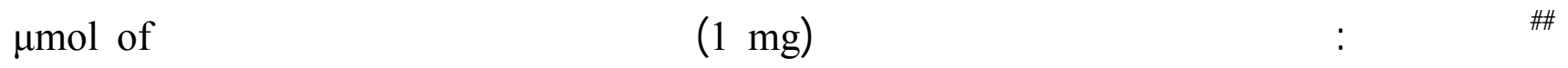
.(NADH/min/mg of protein) 
الجدول 2: خلاصة نتائج مرلل تقية أنزيمي كلوتلمينسنثيتيز وكلوتلمي ـت يهي ـدروجنيز م ـن ن سبه الكل م المصب

\begin{tabular}{|c|c|c|c|c|c|c|c|c|c|c|}
\hline \% & مرل & 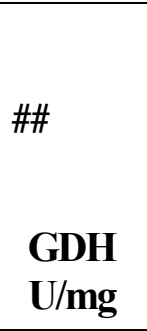 & $\begin{array}{c}\text { كليةلية } \\
\text { GDH } \\
\text { \# U }\end{array}$ & \% Nمتطة & مرل & 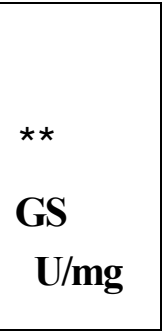 & $\begin{array}{l}\text { لملية } \\
\text { لأنزم } \\
\text { GS } \\
* \text { U }\end{array}$ & لبوتين & $\begin{array}{l}\text { لl } \\
\text { ml }\end{array}$ & مرلل التقية \\
\hline 100.0 & 1.00 & 0.5988 & 467.74 & 100.0 & 1.00 & 0.0593 & 46.31 & 781 & 65.5 & المستخلص الخلم \\
\hline 91.2 & 1.94 & 1.1614 & 426.58 & 93.3 & 1.98 & 0.1176 & 43.19 & 367.3 & 53.8 & المستخلص الرائق \\
\hline 82.5 & 4.03 & 2.4102 & 385.88 & 85.9 & 4.19 & 0.2483 & 39.76 & 160.1 & 10.6 & $\begin{array}{c}\text { الترسيب بكبربتلت } \\
\text { لامونيوم }\end{array}$ \\
\hline 75.5 & 6.56 & 3.9281 & 353.14 & 79.6 & 6.91 & 0.4098 & 36.84 & 89.9 & 13.1 & الغرز الغشائي \\
\hline 64.7 & 12.51 & 7.4908 & 302.63 & 69.0 & 13.34 & 0.7908 & 31.95 & 40.4 & 160.6 & 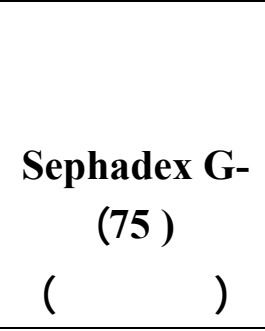 \\
\hline 43.0 & 86.13 & 51.578 & 201.13 & 46.1 & 92.23 & 5.4692 & 21.33 & 3.9 & 18.3 & 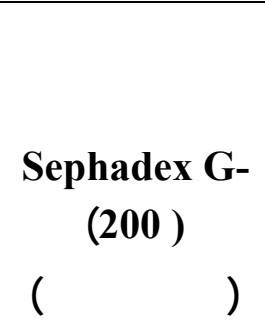 \\
\hline
\end{tabular}




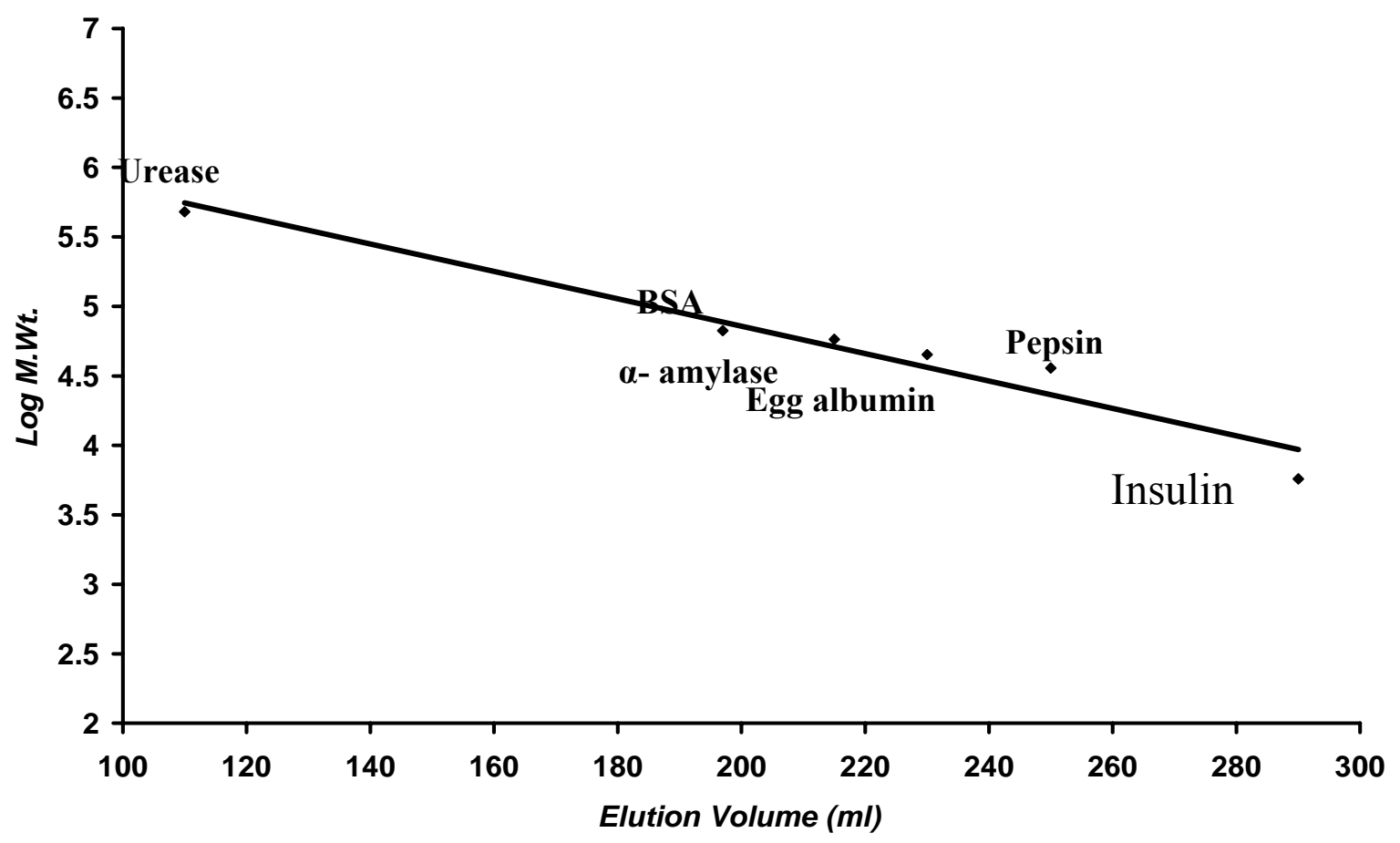

اللشكل 5: المنحني القيلسي لتحديد الوزن الجزيئي بقفنية الترشبح الهلمي بلستخدلم العمود الفصل

الثاني (Sephadex G-200)

ولغرض معرفة الوزن الجزيئي القريبي للوحة الفرعية لأنزيهي GS وGDH المعزولين من i سبيج المبيج

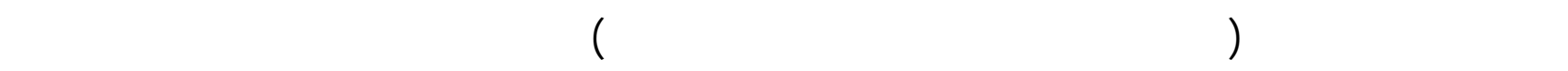

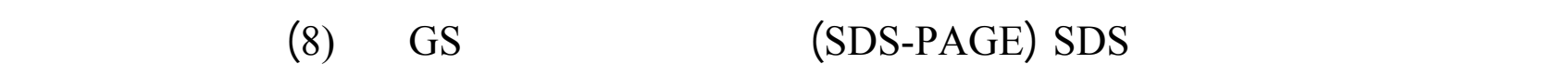

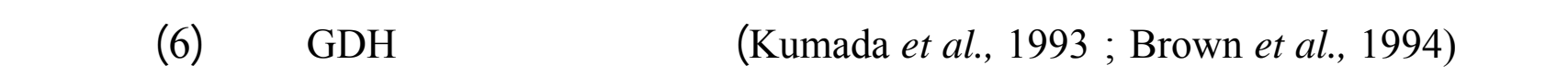
فرعية متماثلة (Britton et al., 1992 ; Dean et al., 1997). واقتد قدر الوزن الجزيئي القريب مي للوح ــة

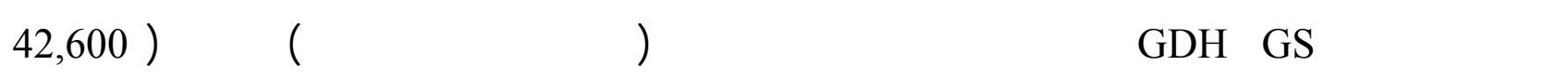
(4 200 Da

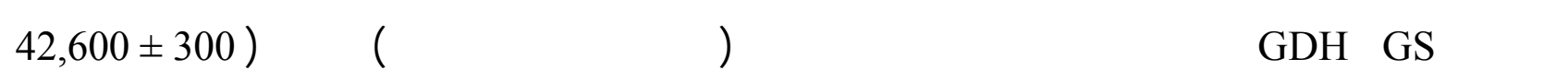

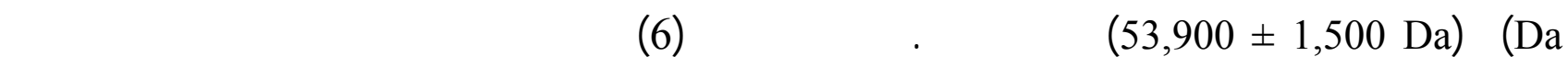

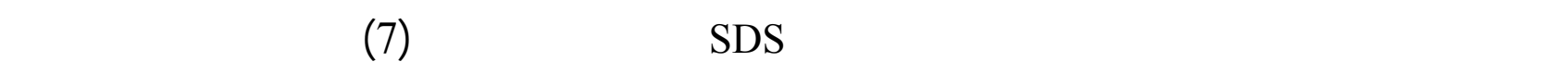

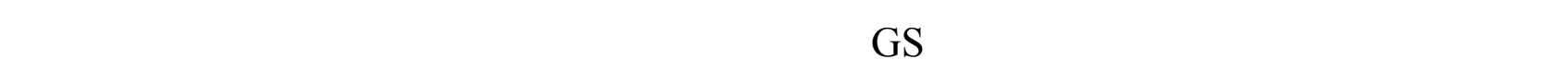

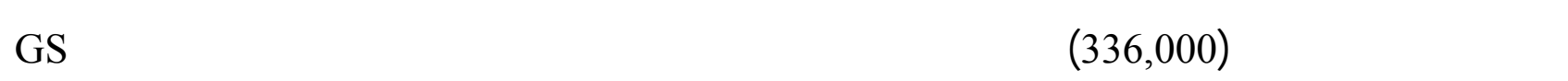

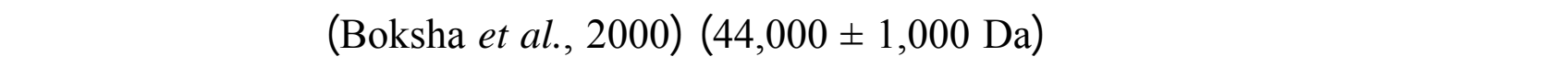

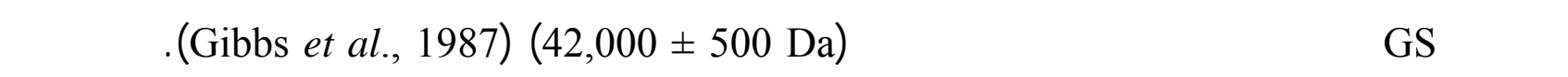




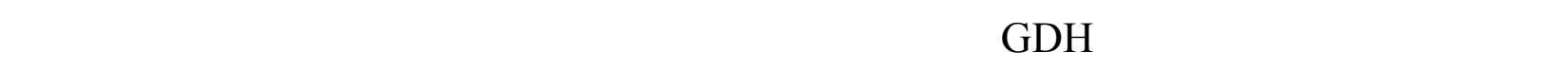

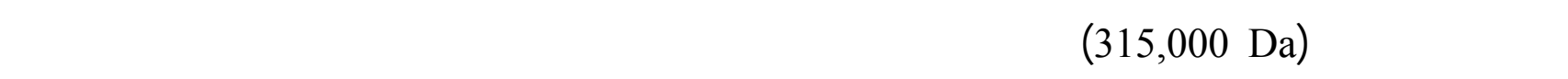

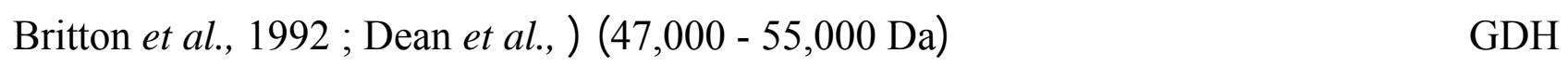

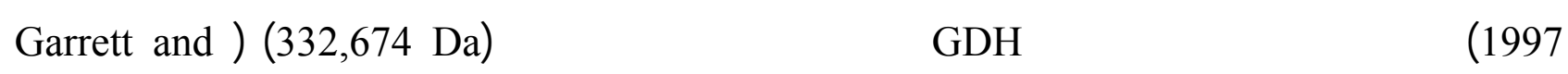
.(Grisham, 2005

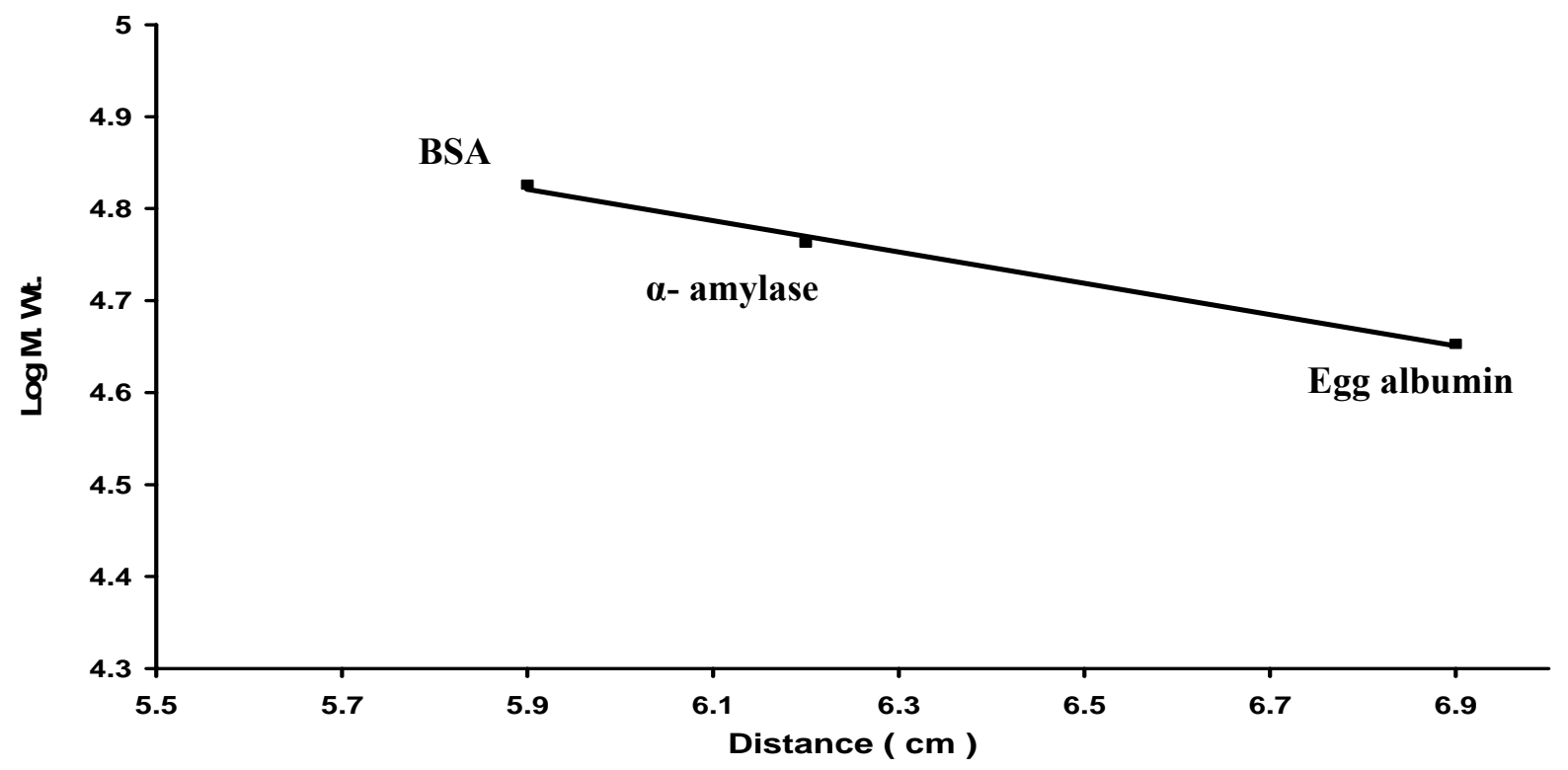

الشكل 6: المنحني القيلسي لتحيد الوزن الجزيئي بقفنية الهجرة الكهربائية الحاوية على SDS (2) صورة تكو صورة رقم (1)

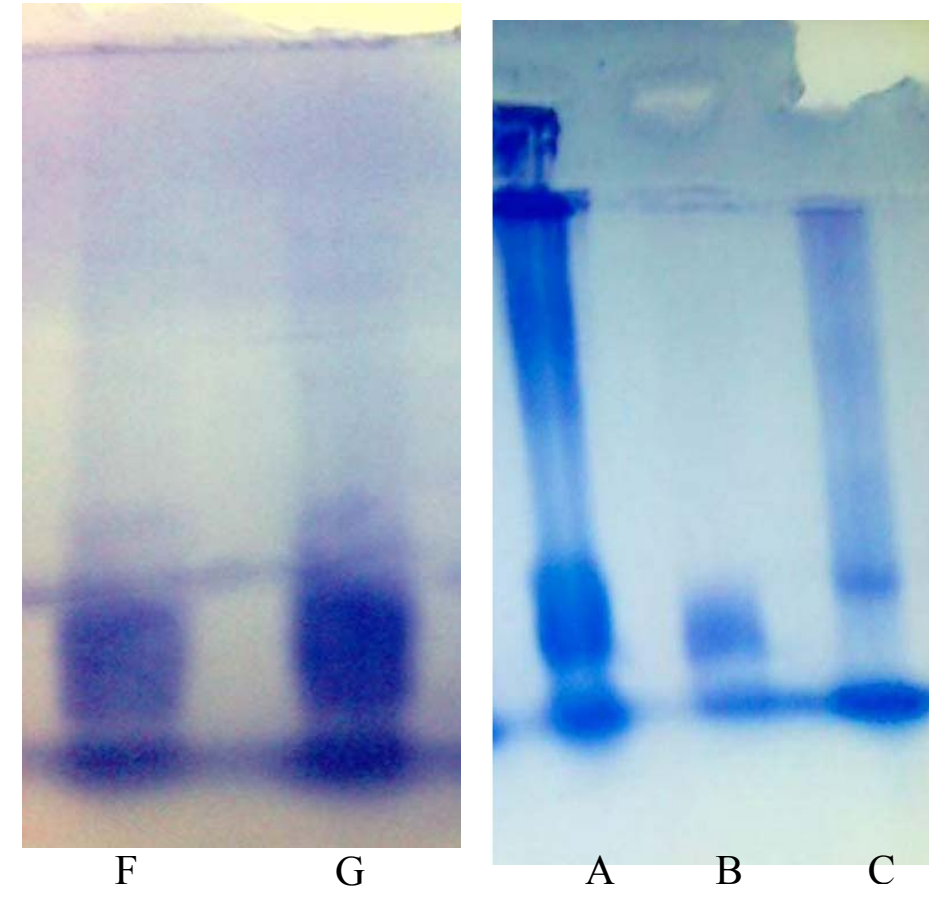

الشكل7: : صور الهجرة لكهربائية الحاوية على SDS حيث أن:

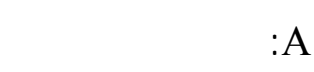
- 1 - أميليز C:ألبومين البيض :

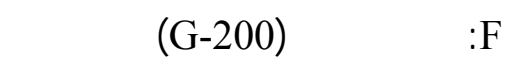

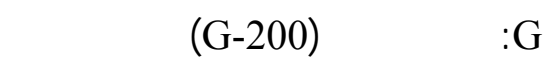




\section{درلسة بهض العوالمل المؤثر عل فعالية الأنزبي GS و GDH المعزولينمن نسبج الكل السليم:} مُ الحزمة البروتينية الثانية (الناتجة من عمود الفصل الثاني) لنسبج الكلى اللسليم كمصدر لكل مل من أنزيم كلوتلمينسنثيتيز وكلوتلميت ديهيدروجينيز.

\section{1. درلسة تأثير بهضن العولمل على فعالية ألنزجم GS المق جزئياً من نسبج الكل السليم:}

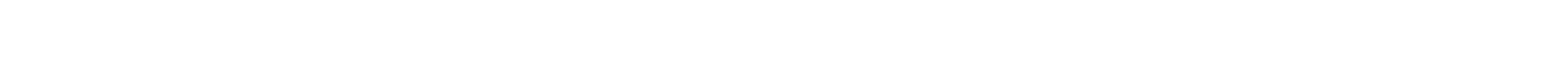

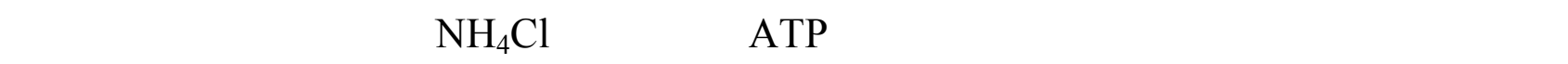

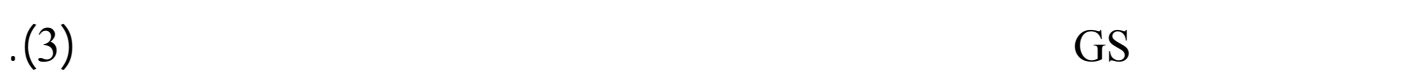
الجدول3: اظطوف المثلى اقيلس فعالية أنزيم كلوتلمينسنثيتيز المقى جزئياً من نسج الكلى للسليم

\begin{tabular}{|c|c|c|c|c|c|c|}
\hline $\begin{array}{c}\text { تركيزماسة } \\
\mathrm{NH}_{4} \mathrm{Cl} \\
(\mathrm{mM})\end{array}$ & $\begin{array}{c}\text { تركيز } \\
\text { ATP } \\
\text { (mM) }\end{array}$ & $\begin{array}{l}\text { السكلميز } \\
\text { السلة } \\
\text { (mM) }\end{array}$ & 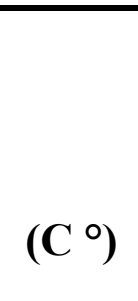 & 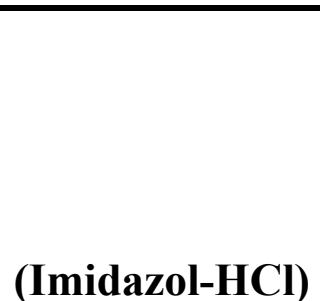 & $\begin{array}{l}\text { زمن } \\
\text { الفالى } \\
\text { (min) }\end{array}$ & $\begin{array}{c}\text { تأنزكيم } \\
\text { ( } \mu \mathrm{gg} / \mathrm{ml})\end{array}$ \\
\hline 1 & 4 & 15 & * 37 & $\begin{array}{c}(100 \mathrm{mM}) \\
\mathrm{pH}=7.2\end{array}$ & 15 & 60 \\
\hline
\end{tabular}

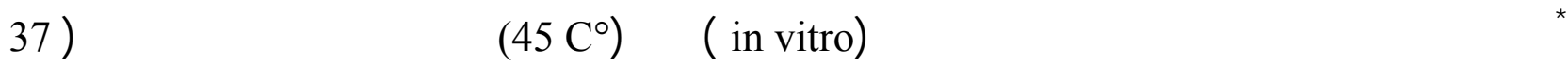

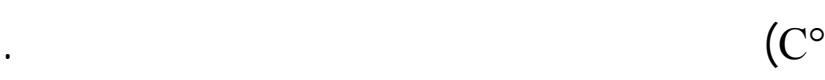

حيث أثارت الأبييت إلى أن التركيز الأمل والأس الهدروجيني الأمثل للأنزيم بلس تخددم المحل ـول المظم ( Imidazol-HCl ) هو (100 mM) و(7.2) على التوالي(McCormik et al., 1982)، وكذك يعهل

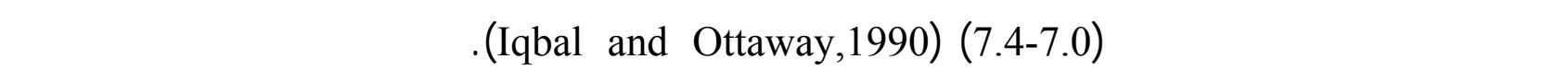

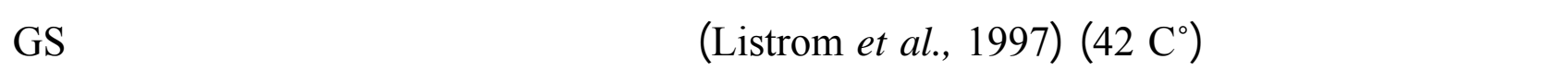

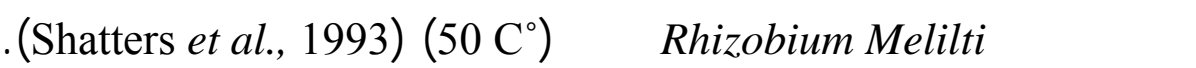

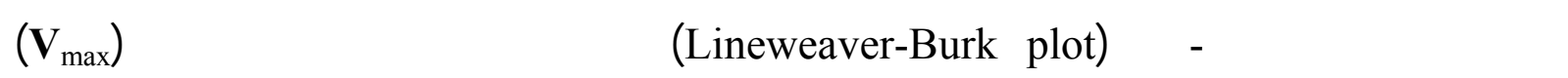

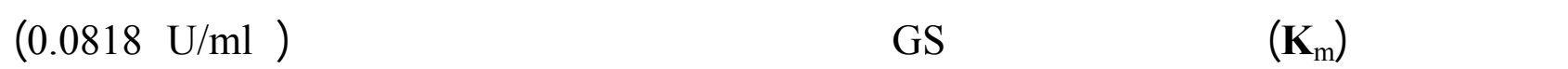
و(11.97 mM على التوالي وكما موضح في اللشكل (8) .

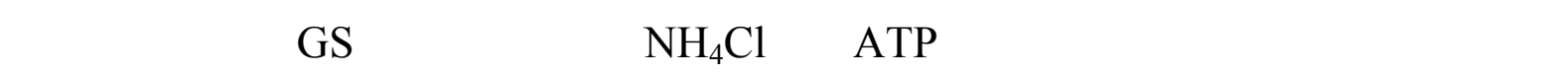

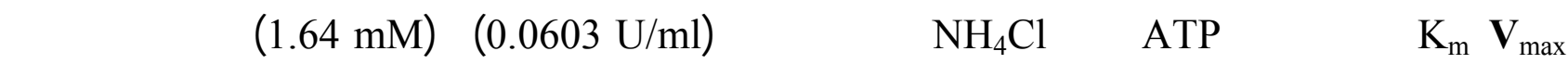

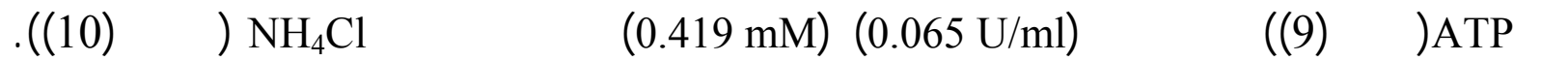




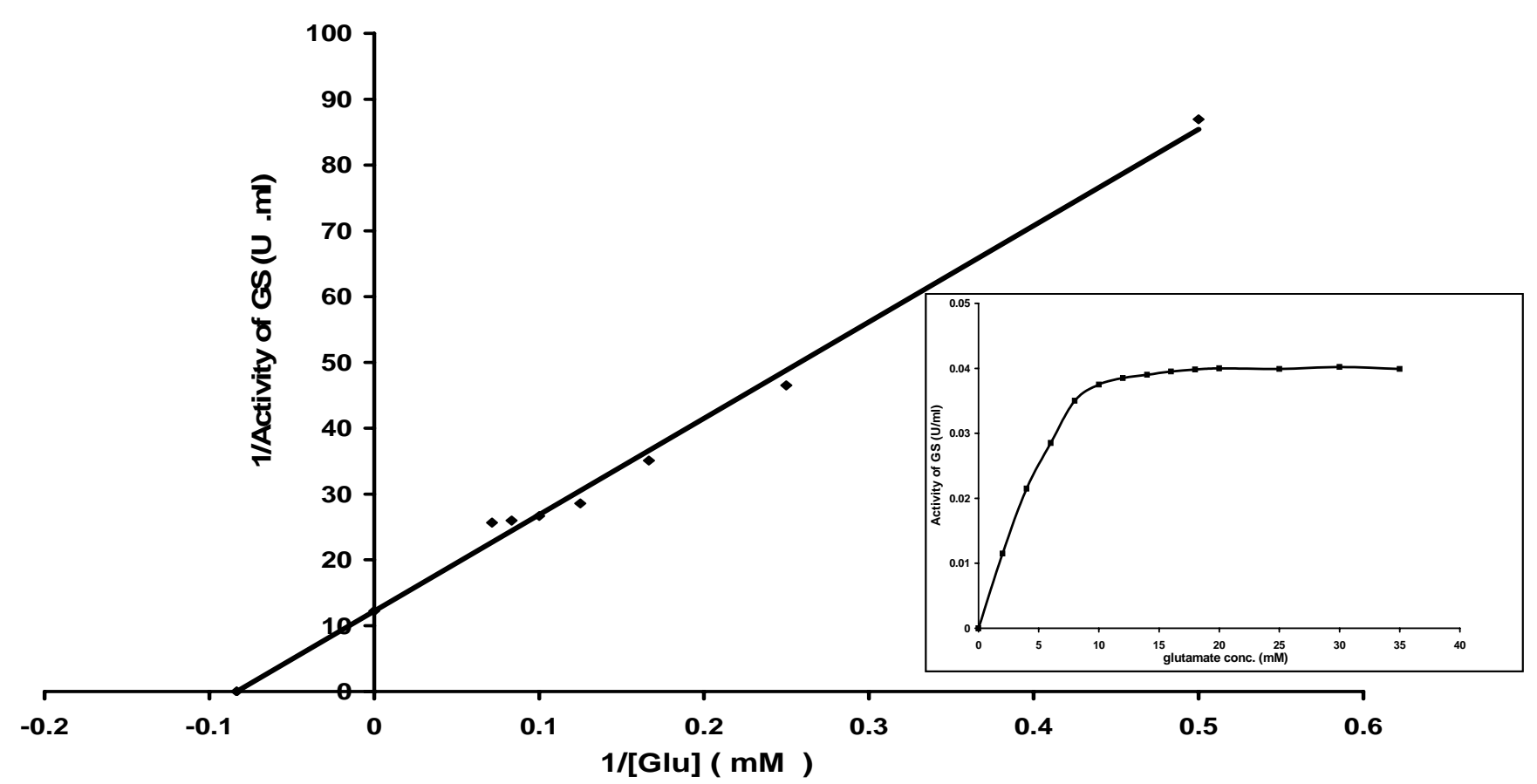

للثكل 8: لسم لاينويفر-برك لتوضبح ثابت ميكيلس وللسرعة القصوى للمادة الأسلس

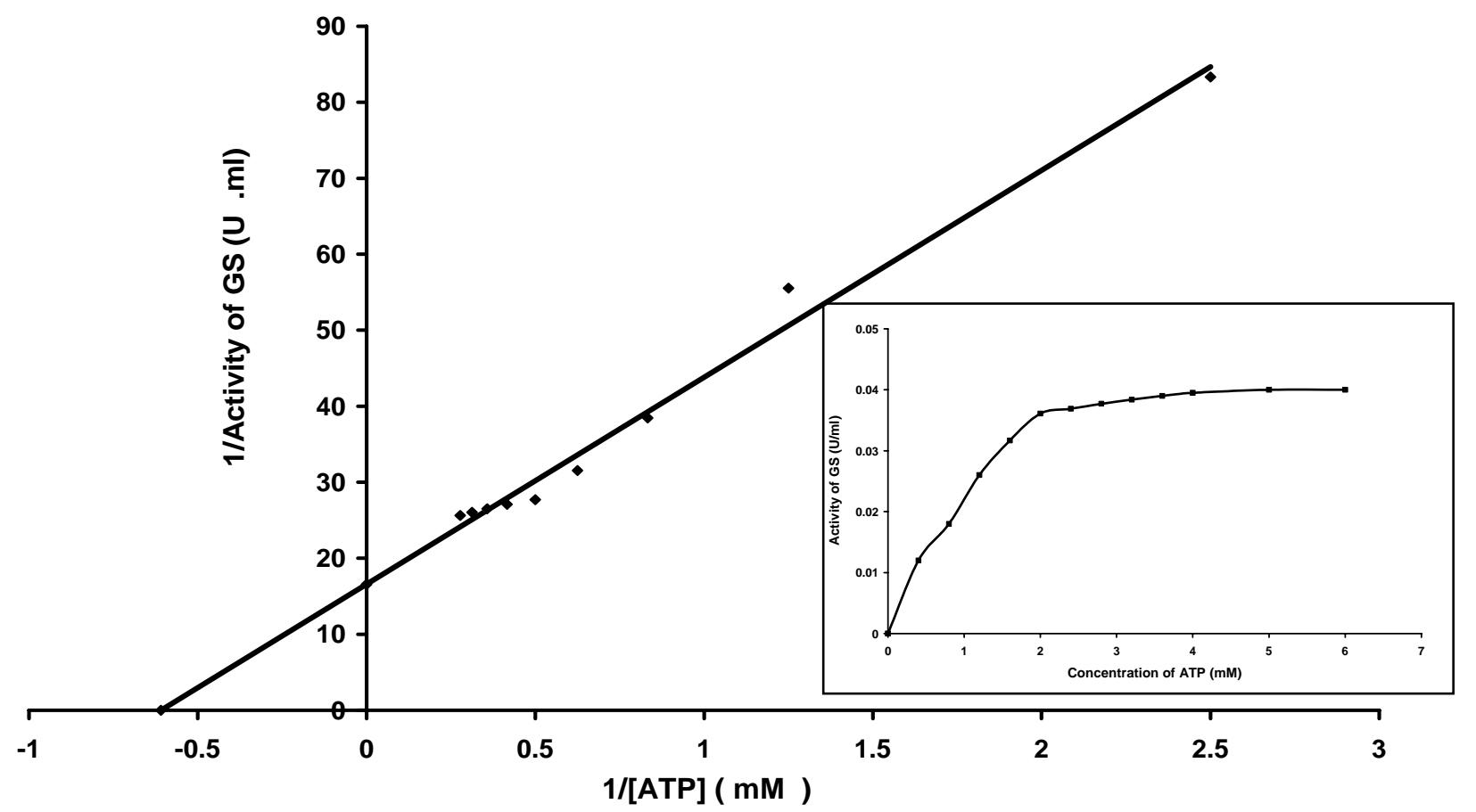

للشكل9 : لسم للينويفر-برك لتوضبح ثابت ميكيلس وللسرعة القصوى للا _ATP 


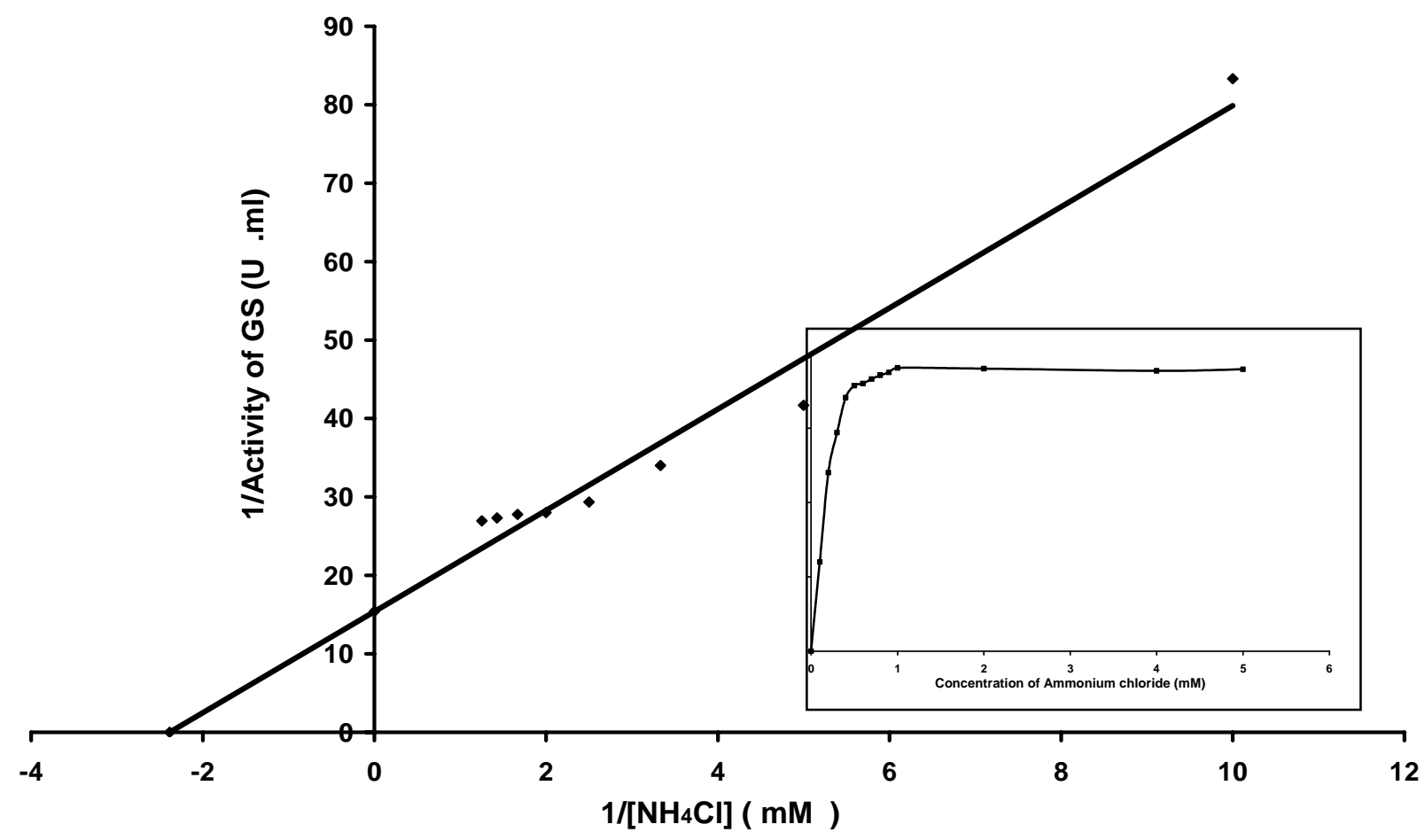

للثكل 10: لسم لاينويفر - برك لتوضبح ثابت ميكيلس وللسرعة القصوى لل _NH4Cl

\section{2. درلسة تأثير بهض العولل عل فعالية ألنزم GDH المق جزئياً من نسبج الهل السليم:}

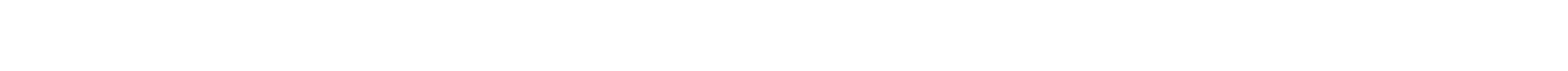

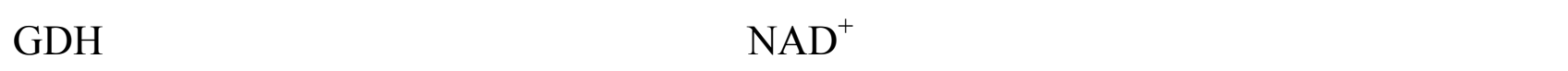
المقى جزئياً من نسيج الكلى اللسليم وكما هوموضير المانة المنين في الجدول (4).

الجدول4: الظاروف المثل لقيلس فعالية أنزيم كلوتلميت يهيدروجينيز المقى جزئياً من شسبج الكلى اللسليمة

\begin{tabular}{|c|c|c|c|c|c|}
\hline $\begin{array}{c}\text { تركيز } \\
\text { ملرك) } \\
\text { NAD } \\
\text { (mM) }\end{array}$ & تركيزماة & $\begin{array}{c}\text { الحرالرة } \\
\text { اجة }{ }^{\circ} \text { (C) }\end{array}$ & 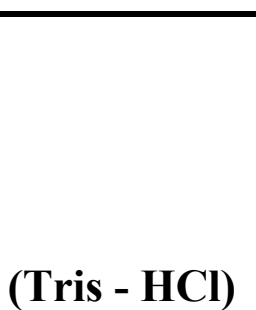 & $\begin{array}{c}\text { زلفن } \\
\text { الغال } \\
\text { (min) }\end{array}$ & $\begin{array}{c}\text { تركيز الأنزجم } \\
\text { (بg/ml) }\end{array}$ \\
\hline 4 & 50 & * 37 & $\begin{array}{c}(100 \mathrm{mM}) \\
\mathrm{pH}=8.8\end{array}$ & 1.0 & 50 \\
\hline
\end{tabular}

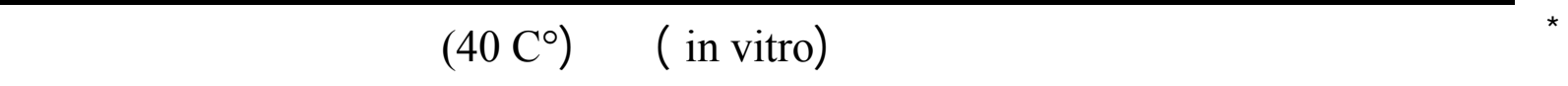

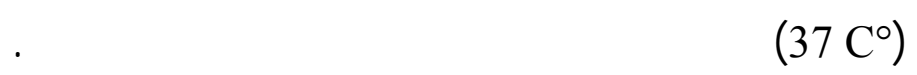


حيث أشارت الأبيلت إلى أن التركيز الأمث لـ للمحل ـول الم ظظم (Tris - HCl) هـ -و (100 mM)

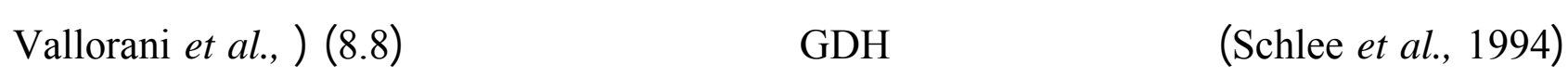

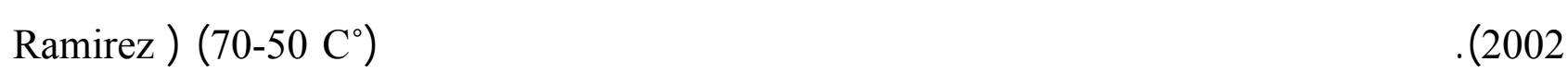
. (Schlee et al., 1994) (70 C C al., 1977

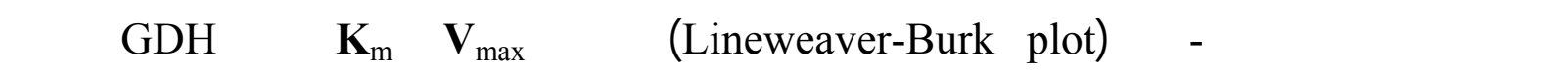

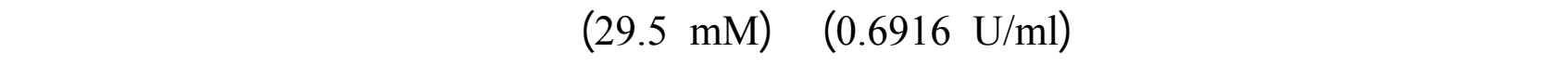

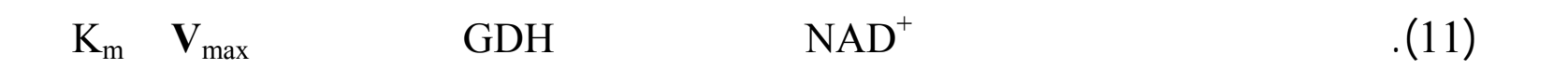
NAD والتي بلغت (0.91 mM) على التوالي اللشكل (12).

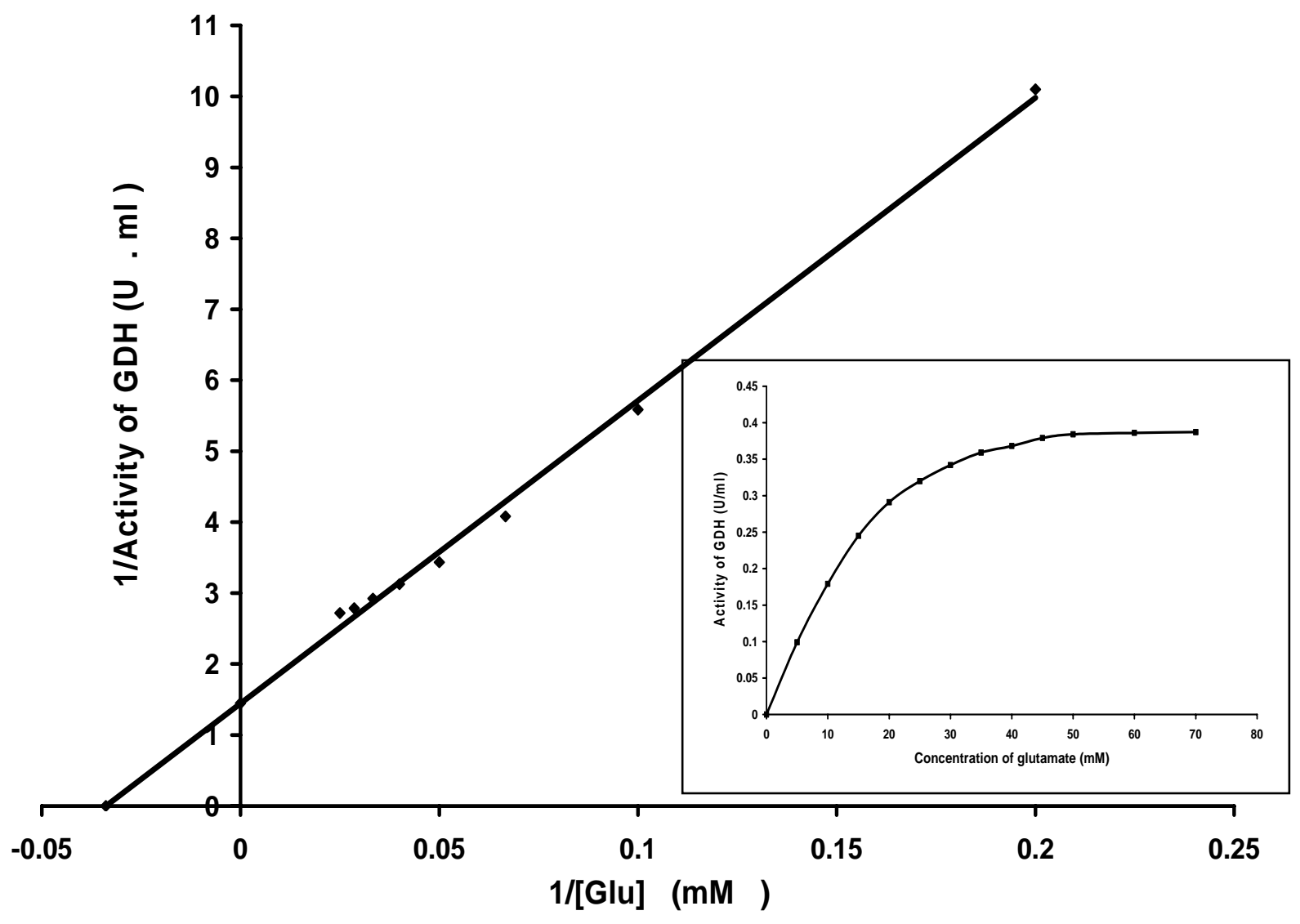

الشكل 11: بم لاينويفر-برك لتوضبح ثابت ميكيلس وللسرعة القصوى للمادة الأسطس 


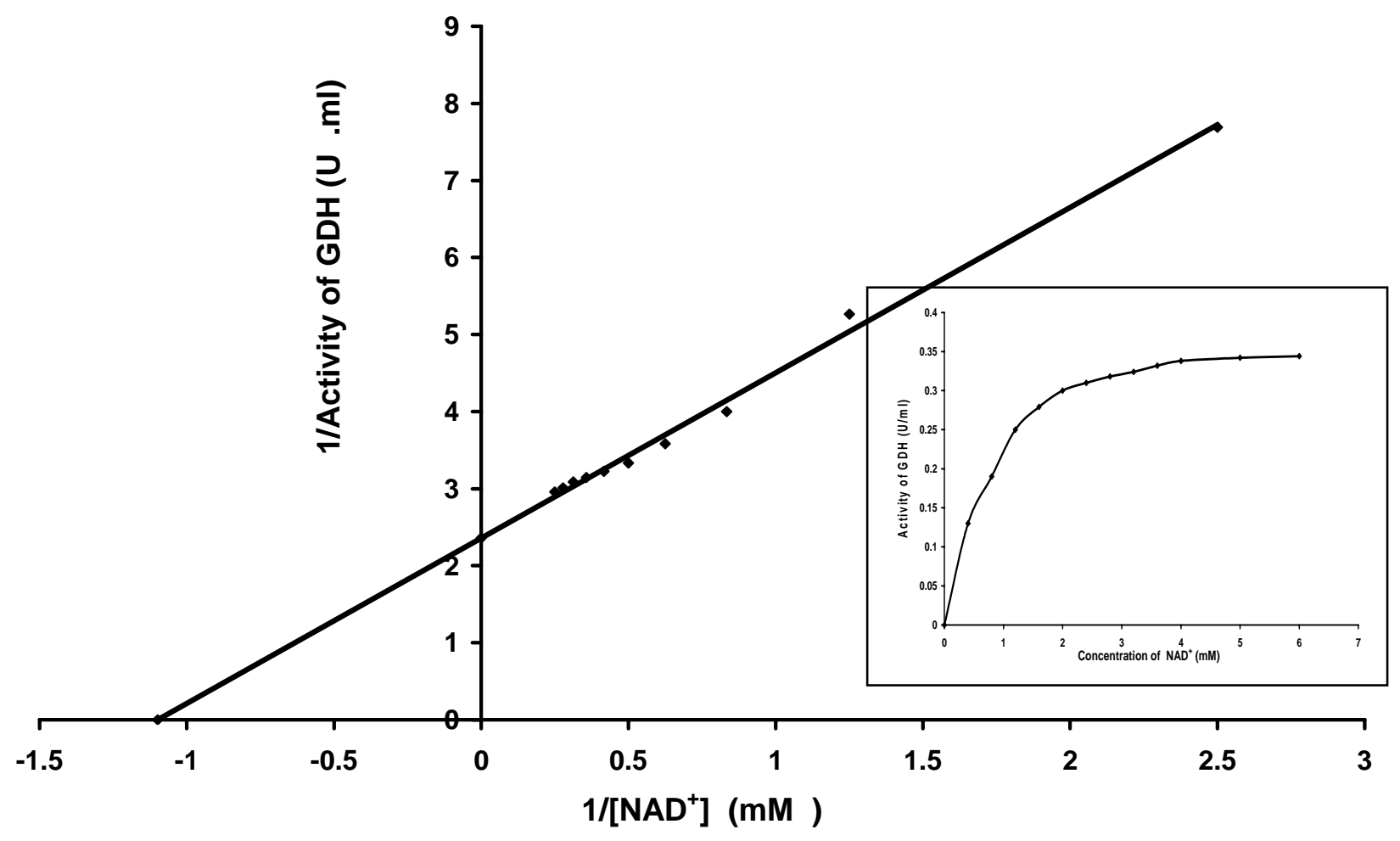

الشكل 12: لسم لاينويفر-برك لتوضبح ثابت ميكيلس وللسرعة القصوى للمادة الـ NAD+

\section{المصاكر الأجنبية}

Andrews, P., 1965. The Gel Filtration Behaviour of Proteins Related to their Molecular Weight Over a Wide Range. J. Biol. Chem., 96: 595p.

Boksha, I. S.; Burbaeva. G. S. and Tereshkina, E. B.,1995. Purification and some Properties of Glutamine Synthetase from Human Brain. Biochem., 60: pp.1299-1303.

Boksha, I. S.; Tereshkina, E. B. and Burbaeva, G. S., 2000. Glutamine Synthetase and Glutamine Synthetase-Like Protein from Human Brain: Purification and Comparative Characterization. J. Neurochem., 75(6): pp.2574-2582 .

Britton, K. L.; Baker, P. J.; Rice, D. W. and Stillman, T. J., 1992. Structural Relationship Between the Hexameric and Teterameric Family of Glutamate Dehydrogenase. Eur. J. Biochem., 209: pp.851-859 .

Brown, J. R., Masuchi, Y., Robb, F. T. and Doolittle, W. F., 1994. Evolutionary Relationships of Bacterial and Arehaeal Glutamine Synthetase Genes. J .Mol. Evol., 38 (6): pp.566-576.

Dean, J. L. E., Cölfen, H., Harding, S. E., Rice, D. W. and Engel, P. C., 1997. Alteration of the Quaternary Structure of Glutamate Dehydrogenase from Clostridium Symbiosum by a Single Mutation Distant from the Subunit. Interfaces. Eur. Biophy. J., 25: pp.417-422 .

Dioxin, M. and Weeb, E. C., 1961. Tools of Biochemistry., John Wiley and Sons, Inc., New York, 370p. 
Edwards, C. R. W. and Bouchier, J. A. D., 1991. Davidson's Principles and Practice of Medicine a Textbook for Students and Doctors. 16th Edn., ELBS with Churchill Livingstone, pp. $230-246$.

Fang, J., Hsu, B. Y. L., MacMullen, C. M., Poncz, M., Smith, T. J. and Stanley, C. A., 2002. Expression, Purification and Characterization of Human Glutamate Dehydrogenase (Gdh) Allosteric Regulator Mutations. Biochem. J., 363: pp. 81-87.

Garnick, M. B. and Richie, J. P., 1996. Renal Neoplasia. in Brenner, B. M., the Kidney. Vol. 2 , 5th Edn., W. B. Saunders Comp., U.S.A., Philadelphia, pp. 1959-1977.

Garrett, R. H. and Grisham, C. M., 2005. Biochemistry. 3rd Edn, Thomson Leaving, Inc., Belmont U.S.A., 107: pp. 815-816.

Gibbs, C. S., Campbell, K. W. and wilson, R. H.,1987. Sequence of Human Glutamine Synthetase Cdna. Nucleic Acid Res., 15: 6293p.

Hadži, V. and ŜKaloviĉ, T., 1990. Properties of Glutamate Dehydrogenase from Developing Maize Endosperm. Physiol. Plant., 80: pp. 238-242 .

Iqbal, K. and Ottaway, J. H., 1970. Glutamine Synthetase in Muscle and Kidney. Biochem. J., 119: pp. 145-158.

Kim, D. W., Eum, W. S., Jang, S. H., Yoon , C. S., Kim, Y. H., Choi, S. H., Choi, H. S.;Kim, S. Y., Kwon, H. Y., Kang, J. H., Kwon, O. S., Cho, S. W., park, J. and Choi, S.Y., 2003. Molecular Gene Cloning, Expression, and Characterization of Bovine Brain Glutamate Dehydrogenase. J. Biochem. Mol. Biol., 36: pp. 545-551.

Krajnc, D., Neff , N. H. and Hadjiconstantinou, M., 1996. Glutamate, Glutamine and Glutamine Synthetase in the Neonatal Rat Brain Following Hypoxia. Bran Res., 707: pp. 134-137.

Kumada , Y., Benson, D. R., Hillemann, D., Hosted, T. J., Rochefort, D. A., Thompson, C. J., Wohlleben, W. and Tateno, Y.,1993. Evolution of the Glutamine Synthetase Gene, one of the Oldest Existing and Functioning Genes. Proc. Natl. Acad. Sci. U. S. A., 90:pp. 3009-3013 .

Laemmli, U. K.,1970. Cleavage of Structural Proteins During the Assembly of the Head of Bacteriophage T4. Nature, 227: pp. 680- 685.

LePrince, G., Delaere, P., Fages, C., Lefrancois, T., Touret, M., Salanon, M. and Tardy M.,1995. Glutamine Synthetase Expression is Reduced in Senile Dementia of the Al-Zheimer Type. Nearochem. Res., 20 : pp. 859-862 .

Listrom, C. D., Morizono, H., RaJagopal, B. S., MeCann, M. T., Tuchman, M. and Allewell, N. M.,1997. Expression, Purification and Pharacterization of Recombinant Haman Glutamine Synthetase . Biochem. J., 328: pp.159-163 .

Lowry, O. H., Rosebrough, N. J., Farr, A. L. and Randall, R. J.,1951. Protein measurement with Folin-Phenol Reagent. J. Biol. Chem., 193: pp. 265-275.

McCormick, D.A., Clark, G.A., Lavond, D.G. and Thompson, R.F., 1982. Initial localization of the Memory Trace for a Basic form of Learning. Proc. Natl. Acad. Sci. U.S.A., 79: pp. 2731-2735.

Murray, R. K., Granner, D. K. and Mayes, P. A.,2000. A Lange Medical Book Harper's Biochemistry. 25th Ed,., McGraw-Hill Comp., New York, pp. 809, 568, 787 .

Plummer, T. D.,1978. An Introduction to Practical Biochemistry. 2nd Ed., McGraw - Hill Book Comp., U. K. 
Ramirez, H., Delagado, J. M. and Garcia Peregmin, E., 1977. Some Properties of Glutamate Dehydrogenase from Agave Americana (1.) Leaves. Pfanzenphysiol., 84: pp.109-119.

Schacterle, G. R. and Pollack, R. L.,1973. A Simplified Method for the Quantitative Assay of Small Amount of Protein in Biological Material. Anal. Biochem., 51: pp.654655 .

Schlee, D., Thöringer, C. and Tintemann, H.,1994. Purification and Properties of Glutamate Dehydrogenase in Scots pine Pinus Sylvestris Needles. Physiol. Plant., 92: pp. 467-472 .

Shapiro, B. M. and Stadtman, E. R.,1970. Glutamine Synthetase (Escherichia coli). in Tabor, h. and Tabor, W. C. (Eds.), Methods in Enzymology. Vol.17A, Academic Press, New York and London, pp.910-912.

Shatters, R. G., Liu, Y. and kahn, M. L.,1993. Isolation and Charactevization of Novel Glutamine Synthetase from Rhizobium Meliloti. J. Biol. Chem., 268 (1): pp.469475.

Shin, D.; Park, S. and Park, C., 2003. A Splice Variant Acquiring an Extra Transcript Leader Region Decreases the Translation of Glutamine Synthetase Gene. Biochem. J., 374: pp.175-184 .

Smirnov, A. V., Tumani, H., Henne, S., Barchfed, S., Olgemoller, U., Wiltfang, J., Lange, P., Mader, M. and Nau, R.,2000. Clin. Chem. Acta, 292: pp.1-12 .

Smith, T. J., Peterson, P. E., Schmidt, T., Fang, J and Stanley, C., 2001. Structures of Bovine Glutamate Dehgdrogenase Complexes Elucidate the Mechanism of Purine Regulation. J. Mol. Biol., 307: pp.707-720 .

Smith, T. J., Schmidt, T., Fang, J., Wu, J., Siuzdak,G. and Stanley,C. A., 2002. The Structure of Apo Human Glutamate Dehydrogenase Details Subunit Communication and Allostery. J. Mol. Biol., 318: pp.765-777 .

Suarez, I., Bodega, G. and Fernandez, B.,2002. Glutamine Synthetase in Brain Effect of Ammonia. Neurochem. Int., 41: pp.123-142 .

Tateno, Y., 1994. Evolution of Glutamine Synthetase Gene is an Accordance with the Neutral Theory of Molecular Evolution. Jpn. J. Genet., 69: pp. 489-502 .

Timmerman, M., Wilkening, R. B and Regnault, P.,2003. Induction of Glutamate Dehydrogenase in the Ovine Fetal Liver by Dexamethasone in Fusion During Late Gestation. Exp. Biol. Med., 228: pp.100-105.

Vallorani, L., Polidori, E., Sacconi, C., Agostini, D., Pierleoni, R., Piccoli, G., Zeppa, S. and Stocchi, V., 2002. Biochemical and Molecular Characterization of Nadp-Glutamate Dehydrogenase from the Ectomycorrhizal Fungus Tuber Borchii. new phytol., 154: pp.779-790.

Zubay, G. L., 1998. Biochemistry.4th Ed, McGraw-Hill Comp. Inc., U.S.A., pp. 964-1962. 